\title{
Enhanced electrochemical performance and decreased strain of graphite anode by $\mathrm{Li}_{2} \mathrm{SiO}_{3}$ and $\mathrm{Li}_{2} \mathrm{CO}_{3}$ co-modifying
}

\author{
Yao Xiao ${ }^{1}$, Guixin Wang ${ }^{1, *}$, Shuo Zhou ${ }^{1}$, Yuhan Sun ${ }^{1}$, Qiang Zhao ${ }^{1}$, Yichao Gong ${ }^{2}$, Tiecheng Lu ${ }^{2}$, \\ Chunhui Luo ${ }^{1}$, Kangping Yan ${ }^{1}$ \\ ${ }^{1}$ College of Chemical Engineering, Sichuan University, Chengdu 610065, China. \\ ${ }^{2}$ College of Physical Science and Technology, Sichuan University, Chengdu 610065, China
}

\begin{abstract}
:
In order to improve the electrochemical performance and decrease the volume changes of artificial graphite, $\mathrm{Li}_{2} \mathrm{SiO}_{3}$ and $\mathrm{Li}_{2} \mathrm{CO}_{3}$ have been in situ prepared to co-modify the graphite by ball milling and heating the precursors of $\mathrm{Li}_{4} \mathrm{SiO}_{4}$ and graphite.
\end{abstract}

The as-obtained graphite-based samples were characterized using various techniques, and the effects of $\mathrm{Li}_{4} \mathrm{SiO}_{4}$ content were investigated. The results show that the co-modified graphite with $20 \mathrm{wt} . \% \mathrm{Li}_{4} \mathrm{SiO}_{4}$ exhibits the highest reversible capacity and the best cycling performance among the graphite-based samples. Compared to the pristine graphite, the initial reversible capacities of the co-modified graphite with $20 \mathrm{wt} . \% \mathrm{Li}_{4} \mathrm{SiO}_{4}$ respectively increase $10.1 \%, 16.4 \%, 28.9 \%$, and $62.4 \%$ at the current rates of $0.1,1.0,2.0$ and $5.0 \mathrm{C}$, while the capacity fade ratios respectively decrease $3.8 \%, 10.0 \%$, and $23.2 \%$ at the current rates of $1.0,2.0$ and $5.0 \mathrm{C}$ after 50 cycles. Furthermore, co-modification by $\mathrm{Li}_{2} \mathrm{SiO}_{3}$ and $\mathrm{Li}_{2} \mathrm{CO}_{3}$ decreases the polarization degree as well as the charge transfer reaction and diffusion resistances of pure graphite. Non-destructive stress-strain tests were adopted to real time monitor the macroscopic stress safety properties of the cells, and the results indicate that the combination of $\mathrm{Li}_{2} \mathrm{SiO}_{3}$ and $\mathrm{Li}_{2} \mathrm{CO}_{3}$ relieves the swelling of the graphite electrode during cycles, and the stress value of the cell surface decreases $34.4 \%$ after 50 cycles at the current rate of $1.0 \mathrm{C}$. The relationship between residue stress and capacity fade along with possible reaction mechanisms is discussed. The good results pave a novel facile way to enhance the performance of current energy materials using combined lithium salts via in situ reaction.

Keywords: Graphite; Lithium silicate; Co-modification; Electrochemical performance; Stress strain analysis

* Corresponding author.

E-mail: guixin66@scu.edu.cn, guixinwang1@gmail.com, Tel: 86-28-85467527

(C) 2016. This manuscript version is made available under the Elsevier user license http://www.elsevier.com/open-access/userlicense/1.0/ 


\section{Introduction}

With the development of advanced lithium-ion batteries, some performances, such as high capacity, good rate performance and long cycle life, are focused for the extensive applications in some fields such as mobile phones, laptops, (hybrid) electric vehicles and other electronic products.[1] As the key anode material for current commercial lithium-ion batteries, graphites, including natural graphite and artificial graphite, have the unique advantages like low charge/discharge voltage platform and lots of raw materials.[2] However, their applications are limited by some issues, such as poor cycling performance, low capacity, large volume change, and possible dendrite formation which could cause short circuit and potential safety hazards.[3-6] Thus, many approaches, including surface treatment, coating, and doping, have been utilized to modify graphite for good performance. For example, oxidization at $550^{\circ} \mathrm{C}$ in air improves the electrochemical performance of graphite,[7] and fluorine gas treatment at $550^{\circ} \mathrm{C}$ enhances the cycling performance of graphite by forming fluorine-graphite intercalation compounds.[8] Amorphous carbon on the graphite surface inhibits the insertion of lithium complex into graphite interlayer, and increases the charge-discharge efficiency.[9] Compared to the natural graphite with soft properties, artificial graphite has many advantages like higher liquid-absorbent capacity, better cycling performance, more extensive sources, along with adjustable microstructure and morphology. Furthermore, artificial graphite can be facilely modified from its raw materials and preparation process. Therefore, artificial graphite is chosen for the research.

Silicon materials are also attractive candidates for next-generation lithium-ion batteries due to their properties like high theoretical capacity,[10-13] low operation potential and abundance in the world. However, the key challenges for the practical applications of silicon anodes are the large volume swelling during lithiation and delithiation processes and low cycle life.[14-16] Recently, different measures have 
been adopted to overcome the problems. Silicon nanowires in porous carbon, synthesized by a supercritical fluid-liquid-solid process, exhibits lower charge transfer resistances, higher specific capacities and better charge-discharge cycling stabilities.[17] Silicon oxides have been used to enhance the cycling performance of silicon anodes, and the nanostructured $\mathrm{SiO}_{2} / \mathrm{C}$ composites, prepared using $\mathrm{SiO}_{2}$ nanoparticles incorporated polyacrylonitrile fibers via electrospinning and subsequent thermal treatment, exhibit high reversible capacities and stable cycling performances.[18] However, both silicon and silicon oxide still have the similar shortcomings of poor cycling performance and low capacity at high current rates. Furthermore, such silicon materials will consume plenty of lithium ions to form lithium silicate products during first discharge process, which decreases the lithium ion content in the cells to harm the cycling performance. Therefore, lithium silicates are regarded as a good alternative to substitute for silicon without decreasing the lithium ion concentration in batteries during cycles. $\mathrm{Li}_{2} \mathrm{SiO}_{3}$ has been utilized to enhance the performance of some electrode materials. For example, $\mathrm{Li}_{2} \mathrm{SiO}_{3}$ improves the velocity of $\mathrm{Li}^{+}$-migration on the surface of the electrode, and enhance both the cycling and rate capabilities of the Li-rich layered cathode material.[9] Furthermore, amorphous $\mathrm{Li}_{2} \mathrm{SiO}_{3}$ improves electronic conductivity by provided uniform carbon coating layer and lithium ion diffusion channels.[19] However, the influence of $\mathrm{Li}_{2} \mathrm{SiO}_{3}$ on graphite anode is still not clear besides the complex synthesis process. On the other hand, $\mathrm{Li}_{2} \mathrm{CO}_{3}$ has been used as an effective additive to enhance the reversibility and cyclability of graphite by favoring the formation of compact and stablesolid electrolyte interface (SEI) film.[20] However, $\mathrm{Li}_{2} \mathrm{CO}_{3}$ is rarely soluble in organic electrolyte, which makes it difficult to prepare an electrolyte containing $\mathrm{Li}_{2} \mathrm{CO}_{3}$. As an interesting solid tritium material in fusion reactors, $\mathrm{Li}_{4} \mathrm{SiO}_{4}$ has high lithium atom density and good mechanical stability,[21] but will decompose into $\mathrm{Li}_{2} \mathrm{SiO}_{3}$ and $\mathrm{Li}_{2} \mathrm{O}$ when the ambient temperature ranges from $500^{\circ} \mathrm{C}$ to $700^{\circ} \mathrm{C},[22]$ and the produced $\mathrm{Li}_{2} \mathrm{O}$ will easily react with $\mathrm{CO}_{2}$ in ambient environment to 
form $\mathrm{Li}_{2} \mathrm{CO}_{3}$.

As for the extensive applications of lithium-ion batteries, safety issues, such as swelling, leakage, explosion and burning, have to be seriously considered for sustainable development.[23] In fact, a sealed cell is a typical pressure vessel with thin shell, and the hazards usually take place when the maximum inner stress is higher than the strength of the outer shell, which could cause the severe damages on the whole power system, even human beings and ambient environments. Compared to the temperature which is extensively used in the safety management for current batteries, stress is much more quickly, more accurate, and more related to the hazards according the failure analysis of batteries. Therefore, it is vital and essential to monitor the stress changes and take precautions against the potential hazards of batteries. The microscopic stress from the particles in active materials has been discussed,[24-26] but the typical safety issues are directly related to the macroscopic stress in cells, which has not yet been carefully considered. Such stress, including the microscale stress from particles and other stresses from heat, reaction, volume changes, is very complex as a combined result of the interaction between particles, thermal expansion, interaction between electrode and electrolyte, electrochemical reaction, transport of ions, and so on. A nondestructive method has been successively developed to real-time monitor the surface macroscopic stress changes of $\mathrm{Li}\left(\mathrm{Ni}_{1 / 3} \mathrm{Co}_{1 / 3} \mathrm{Mn}_{1 / 3}\right) \mathrm{O}_{2}$ cells using strain-stress tests.[27]

In this work, $\mathrm{Li}_{2} \mathrm{SiO}_{3}$ and $\mathrm{Li}_{2} \mathrm{CO}_{3}$ were considered to co-modify the commercial artificial graphite, and the samples were in situ synthesized by ball milling and heating the mixture of $\mathrm{Li}_{4} \mathrm{SiO}_{4}$ and graphite. The electrochemical performance and stress safety properties of the co-modified graphite electrodes were investigated in detail and the possible reaction mechanisms were discussed. 


\section{Experimental}

\subsection{Materials synthesis}

The $\mathrm{Li}_{4} \mathrm{SiO}_{4}$ was synthesized using the precursor powders obtained by a hydrothermal process, and has unique pore structure and small homogeneous particle size (average $0.67 \sim \mu \mathrm{m}$ ). [28] The co-modified graphite samples were in situ prepared by mechanical ball milling the mixture of artificial graphite and $\mathrm{Li}_{4} \mathrm{SiO}_{4}$ with various mass ratios, and then heating at $\sim 600^{\circ} \mathrm{C}$ in $\mathrm{Ar}$ for $4 \sim 6$ hours. According to the mass ratios of 1:0, 5:1, 4:1 and 3:1 of graphite to $\mathrm{Li}_{4} \mathrm{SiO}_{4}$, the pristine artificial graphite and the modified graphite samples are marked as G, GS51, GS41, and GS31, respectively. In order to investigate the influence of ball milling and heat treatment on the pure graphite and detect the difference from the pristine graphite $\mathrm{G}$, the pure graphite with the same ball milling and thermal treatment as that of the samples of GS51, GS41, and GS31 is names as GS10.

\subsection{Materials characterization}

Compositions and phase structure of the samples were examined by an X-ray diffractometer (XRD, Philips X'Pert Pro, Netherland) with $\mathrm{Cu} \mathrm{K}_{\alpha}$ radiation, and the scanning range is from 15 to $85^{\circ}$ with a step of $4 \% \mathrm{~min}$. The morphologies were observed using a scanning electron microscope (SEM, JEOL JSM5900LV, Japan).

\subsection{Electrochemical evaluation}

The electrochemical performance was evaluated using 2025 coin cells consisting of 304 stainless steel (SS) via the techniques like galvanostatic charge/discharge tests, cyclic voltammetry (CV) and electrochemical impedance spectrogram (EIS). Both the pristine and the as-synthesized graphite samples 
were ground and then mixed well with $10 \mathrm{wt} . \%$ of conductive acetylene black and $10 \mathrm{wt} . \%$ of commercial LA-132 binder (Chengdu Indigo Power Sources Co. Ltd., China) to prepare electrodes. The mixture was further mechanically homogenized in an agate mortar to form even slurry for coating on a cleaned copper foil. After being dried at $100^{\circ} \mathrm{C}$ under vacuum for at least 10 hours, the foil was laminated and cut into 1.2 $\mathrm{cm}^{2}$ wafers for use as working electrode. The loading density of the active material is $\sim 0.48 \mathrm{mg} \mathrm{cm}^{-2}$. Metal lithium was used as both the counter and reference electrode.[29, 30] In an argon-filled glove box, 2025 cells were assembled by sandwiching a Celgard 2300 microporous separator between two electrodes using an electrolyte of 1.0 $\mathrm{M} \mathrm{LiPF}_{6}$ dissolved in a solution of ethylene carbonate (EC), dimethyl carbonate (DMC) and ethyl methyl carbonate (EMC) $(1: 1: 1$ in volume, Shenzhen Capchem Chemicals Co. Ltd., China). The above cells were galvanostatically charged/discharged between 0.01 and $2.00 \mathrm{~V} v s . \mathrm{Li}^{+} / \mathrm{Li}$ at room temperature on a Neware battery-testing instrument (Shenzhen Neware Technology Ltd., China). CV and EIS tests were performed on an electrochemical work station consisting of PAR273A and signal recovery model 5210 lock-in-amplifier controlled by Powersuite software (Princeton Applied Research, USA). The potential window of the CV curves is same as that of the galvanostatic tests, and the EIS frequency range is from $100 \mathrm{kHz}$ to $10 \mathrm{mHz}$ with a sinusoidal excitation voltage of $10 \mathrm{mV}$. In order to compare the capacity differences between various samples, the specific capacities of all samples is based on pure graphite

\subsection{Stress-strain tests}

The stress-strain and electrochemical testing system is supplied in Figure 1. Because the cell case is composed of 304 stainless steel, metal resistance strain gauges (Zhonghang Electronic Measuring Instruments Co. Ltd., China) are chosen for measuring the strains and consequently evaluating the stresses in lithium ion cells under different conditions. After being adhered to the cathode shell of the above 2025 
cells without wave spring, the strain gauges are connected to a stress-strain testing system (Donghua testing technology Co. LTD, China). The strain gauge has a size $0.3 \times 1.8 \mathrm{~mm}$ and a maximum strain range of $\sim 2 \%$, and consists of a grid of wire filament on an insulated rear side which supports a metallic foil pattern. The accuracy and the resistance of the strain gauge are about $1 \mu \varepsilon$ and $120 \mathrm{Ohm}$, respectively. The tested cell was fixed in a battery holder which is communicated to a battery testing system (Shenzhen Neware Technology Ltd., China). Both cycling process and stress-strain tests of the cells proceed simultaneously.

\section{Results and discussion}

\subsection{XRD analysis}

In order to detect the compositions of the samples with different mass ratios, their XRD patterns are compared in Figure 2. The XRD patterns of all samples appear the typical characteristic peaks of graphite at $2 \theta=26.4,42.2,44.4,54.5,59.7,77.2,82.2^{\circ}$, indicating the existence of graphite in all the samples. On the other hand, the weak peaks at $2 \theta=22.3,22.7,24.2,26.9,28.2,30.6,31.7,33.2,33.9,34.8,38.6^{\circ}$, appear in the patterns of GS51 and GS31, indicating the existence of $\mathrm{Li}_{2} \mathrm{SiO}_{3}, \mathrm{Li}_{4} \mathrm{SiO}_{4}$ and $\mathrm{Li}_{2} \mathrm{CO}_{3}$. However, the peaks corresponding to $\mathrm{Li}_{4} \mathrm{SiO}_{4}$ at $2 \theta=16.8,17.3,22.3,22.7,24.2,28.2,29.3,33.8,34.8,29.3,33.8,34.8^{\circ}$ disappear, while the peaks of $\mathrm{Li}_{2} \mathrm{SiO}_{3}$ at $2 \theta=18.9,27.0,33.1,38.6,51.8,59.2,69.7,72.9^{\circ}$ and $\mathrm{Li}_{2} \mathrm{CO}_{3}$ at $2 \theta=21.3,23.4,30.6,31.7,33.9,36.8^{\circ}$ remain in the pattern of GS41, indicating that the existence of $\mathrm{Li}_{2} \mathrm{SiO}_{3}$ and $\mathrm{Li}_{2} \mathrm{CO}_{3}$. Therefore, proper mass ratio of 4:1 is beneficial for forming the composite without $\mathrm{Li}_{4} \mathrm{SiO}_{4}$ residue, and more or less content of $\mathrm{Li}_{4} \mathrm{SiO}_{4}$ will result in the residue of $\mathrm{Li}_{4} \mathrm{SiO}_{4}$ in the samples. $\mathrm{Li}_{4} \mathrm{SiO}_{4}$ will decompose into $\mathrm{Li}_{2} \mathrm{SiO}_{3}$ and $\mathrm{Li}_{2} \mathrm{O}$ when it is heated at $600^{\circ} \mathrm{C}$, and the reaction is as follows[22] $\mathrm{Li}_{4} \mathrm{SiO}_{4} \stackrel{600^{\circ} \mathrm{C}}{\longrightarrow} \mathrm{Li}_{2} \mathrm{SiO}_{3}+\mathrm{Li}_{2} \mathrm{O}$.

Thus, the produced $\mathrm{Li}_{2} \mathrm{O}$ will react with the $\mathrm{CO}_{2}$ in ambient environment to form $\mathrm{Li}_{2} \mathrm{CO}_{3}$ abiding by 


\section{$\mathrm{Li}_{2} \mathrm{O}+\mathrm{CO}_{2} \rightarrow \mathrm{Li}_{2} \mathrm{CO}_{3}$.}

The $\mathrm{CO}_{2}$ in ambient environment may be from air and the reaction of graphite and the adsorbed oxygen from air. According to the reactions and the $\mathrm{XRD}$ results, excessive $\mathrm{Li}_{4} \mathrm{SiO}_{4}$ will not decompose completely in the limited heating period, while less $\mathrm{Li}_{4} \mathrm{SiO}_{4}$ will be easily covered by graphite particles to prevent complete reaction, which may result in the existence of $\mathrm{Li}_{4} \mathrm{SiO}_{4}$ in the samples of GS51 and GS31.

\subsection{Electrochemical performance}

The typical galvanostatic charge/discharge curves of the samples of G, GS10, GS51, GS41, and GS31 at various current rates are supplied in Figure 3. All the fresh cells were firstly charged/discharged at the current rate of $0.1 \mathrm{C}$ for 3 cycles for activation, and then were cycled at the current rates of 1.0, 2.0, and 5.0 C for 50 cycles, respectively. All the curves exhibit long and flat voltage plateaus, similar to that of graphite, indicating the electrode reaction process has not changed after co-modification, which will be further analyzed by the later EIS and CV results. The length of the voltage plateau of the pristine graphite increases differently with the co-modification by lithium salts, indicating that combined lithium salts enhance the capacity properties in various degrees. The sequence for the capacity increase of graphite is GS41 > GS51 > GS31> GS10 under various current rates, and GS41, GS51, and GS31 improve the initial discharge capacities of graphite by $10.1 \%, 7.6 \%$, and $3.3 \%$ at the current rate of $0.1 \mathrm{C}$, respectively. Noticeably, the initial reversible capacity of Sample GS10 with the same ball milling and heat treatment with other samples of GS41, GS51, and GS31 is $356 \mathrm{mAh} \mathrm{g}^{-1}$ at the current rate of $0.1 \mathrm{C}$, slightly higher than that of pure graphite G. However, Sample GS10 exhibits the lowest initial reversible capacities among all the samples when the current density increases, and the values are as low as 313, 220 and $160 \mathrm{mAh} \mathrm{g}^{-1}$ at the current rates of 1.0, 2.0 and $5.0 \mathrm{C}$, respectively, lower than that of pure graphite $\mathrm{G}$, indicating that only ball milling 
and heat treatment are not beneficial for the rate performance of graphite. Heat treatment makes the graphite slightly expand, increasing the interlayer distance,[5] which increases the initial reversible capacity at the current rate of $0.1 \mathrm{C}$ of the pure graphite G. However, heat treatment of the samples is in a protective atmosphere, and will not form oxide or protective layers which are reported in some reference.[31] This slight expanding graphite are lack of oxide layers, which may cause the graphite layers to easily collapse during repeated insertion and extraction processes of lithium ions,[32] which decreases the initial reversible capacity at high current densities..

On the other hand, Sample GS41 exhibits the highest initial discharge capacities up to $371,357,334$, and $285 \mathrm{mAh} \mathrm{g}^{-1}$ at the current rates of 0.1, 1.0, 2.0 and 5.0 C, respectively, while the capacities of Sample $\mathrm{G}$ are only $334,319,236$, and $150 \mathrm{mAh} \mathrm{g}^{-1}$ at the same current rates, respectively. Furthermore, the Coulombic efficiencies of the initial cycle of GS41 respectively reach $99.6 \%, 99.1 \%$, and $99.0 \%$ at the current rates of 1.0, 2.0, and $5.0 \mathrm{C}$, much higher than that of the pristine graphite at the same conditions, indicating the reversibility of graphite has been improved. In addition, the medium voltage difference between the charge platform and the discharge platform of the co-modified graphite electrode is lower than that of the pristine graphite, indicating a lower polarization degree, which will be further confirmed by the later $\mathrm{CV}$ tests. As for all the samples at various current rates, ball milling and heat treatment decreases the capacities of the pristine graphite at high current rates, and the capacities and Coulombic efficiencies of the GS41 by only $\mathrm{Li}_{2} \mathrm{SiO}_{3}$ and $\mathrm{Li}_{2} \mathrm{CO}_{3}$ co-modifying are the highest, while that of the samples of GS51 and GS31 with $\mathrm{Li}_{2} \mathrm{SiO}_{3}, \mathrm{Li}_{2} \mathrm{CO}_{3}$ and $\mathrm{Li}_{4} \mathrm{SiO}_{4}$ residue co-modification decrease differently in spite that they are still higher than that of the pristine graphite, indicating that the improvement of capacities and reversibility of graphite is from $\mathrm{Li}_{2} \mathrm{SiO}_{3}$ and $\mathrm{Li}_{2} \mathrm{CO}_{3}$, not the ball milling and thermal treatment. The as-synthesized $\mathrm{Li}_{4} \mathrm{SiO}_{4}$ without ball-milling and heat treatment has low capacities and poor cyclability, and the initial 
reversible capacity is only $36.6 \mathrm{mAh} \mathrm{g}^{-1}$ and the corresponding Coulombic efficiency is as low as about $34.7 \%$ at the current rate of $0.2 \mathrm{C}$ besides a quick fade, as shown in Figure $1 \mathrm{~S}$ and $2 \mathrm{~S}$. However, its products obtained by simple ball milling in air and heating in Ar, greatly enhance the electrochemical performance of graphite.

The cycling performances of the samples are compared in Figure 4. In order to evaluate the selfdischarge and recovery behaviors, all the cells were rested for $8 \mathrm{~h}$ before further cycling at the current rate of 5.0 C. Noticeably, Sample GS10 with the same ball milling and heat treatment with other samples of GS41, GS51, and GS31 exhibits the worst cycling performance among the samples, and the capacities only remain $87.9 \%, 61.8 \%$, and $44.9 \%$ of its initial reversible capacities after 30 cycles at the current rates of 1.0 , 2.0 and 5.0 C, respectively. On the other hand, the sample GS41 exhibits the best cycling performance, even after a rest of $8 \mathrm{~h}$, and the capacities maintain $96.2 \%, 90.0 \%$, and $76.8 \%$ of its initial reversible capacities at the current rates of 1.0, 2.0 and 5.0 C, respectively. However, the capacity retention ratios of the pristine graphite are only $95.5 \%, 70.7 \%$ and $44.9 \%$ at the same conditions. In contrast with the pristine graphite, the reversible capacities of the GS41 are increased by $10.1 \%, 16.4 \%, 28.9 \%$, and $62.4 \%$ at the current rates of $0.1,1.0,2.0$, and $5.0 \mathrm{C}$, respectively. Therefore, ball milling and heat treatment are not good for enhancing the rate performance and cyclability of graphite, while co-modification by $\mathrm{Li}_{2} \mathrm{SiO}_{3}$ and $\mathrm{Li}_{2} \mathrm{CO}_{3}$ greatly improves the electrochemical performance (including capacity, reversibility, rate performance, and cyclability) of graphite, which will be further confirmed by the later CV and EIS tests. Furthermore, $\mathrm{Li}_{2} \mathrm{SiO}_{3}$ and $\mathrm{Li}_{2} \mathrm{CO}_{3}$ are very significant for enhancing the electrochemical performance of graphite, while $\mathrm{Li}_{4} \mathrm{SiO}_{4}$ is not good for enhancing the electrochemical performance, which might be from the electrode reaction process and SEI film. 


\subsection{CV analysis}

After one cycle at the current density of $0.1 \mathrm{C}$, the cyclic voltammograms of the GS41 and G cells at the scanning rates of $0.1,0.2,0.5,1.0$ and $2.0 \mathrm{mVs}^{-1}$ between 0.01 and $2.00 \mathrm{~V}$ are shown in Figure 5. One pair of obvious redox peaks of graphite is observed in both CV curves of the samples of GS41 and G, indicating that the capacity is mainly from graphite and co-modification has few effects on the electrochemical reaction process of graphite, agreeing well with the above galvanostatic testing results. The oxidation peak and reduction peak correspond to the charge process and discharge process, respectively. The key parameters, such as oxidization potential $\left(\mathrm{E}_{\mathrm{O}}\right)$, reduction potential $\left(\mathrm{E}_{\mathrm{R}}\right)$, potential difference between oxidization peak and reduction peak $(\Delta \mathrm{E})$, oxidation peak current density (io), and reduction peak current density $\left(\mathrm{i}_{\mathrm{R}}\right)$, are summarized in Table 1 .The relationship between peak current intensity and scanning rates reflects the kinetic characteristics of electrochemical reaction, including solid phase diffusion-controlled or surface-confined charge transfer processes. Noticeably, the cathodic peak potential, corresponding to the voltage platform of the discharge process in which $\mathrm{Li}^{+}$ions intercalate into the graphite, is around $0.17 \mathrm{~V}$ at $0.1 \mathrm{mVs}^{-1}$, and becomes unsharpness gradually with the increase of scanning rate. The reduction peak at $\sim 0.17 \mathrm{~V}$ disappears when the scanning rate is higher than $0.5 \mathrm{mVs}^{-1}$, but the reduction peak close to $0.0 \mathrm{~V}$, which is related to the decomposition of electrolyte,[33] increases with the increase of scanning rate, indicating the capacity fades at high current densities. The anodic peak potential, corresponding to the voltage platform of the charge process in which $\mathrm{Li}^{+}$ions de-intercalate from the lithiation product of $\mathrm{LiC}_{6}$, is around 0.22 Vat $0.1 \mathrm{mVs}^{-1}$, and increases gradually with the increase of scanning rate. Furthermore, the potential difference $\Delta \mathrm{E}$ increases with the increase of scanning rate, indicating the increased polarization. However, GS41 greatly increases the redox peak density as well as retards the decrease of cathodic peak intensity and the increase of potential difference $\Delta \mathrm{E}$, indicating the 
improved reaction activity and decreased polarization. $[34,35]$ Therefore, co-modification by $\mathrm{Li}_{2} \mathrm{SiO}_{3}$ and $\mathrm{Li}_{2} \mathrm{CO}_{3}$ greatly decreases the polarization and increases the electrode reaction activity of the pristine graphite, consistent with the above charge/discharge testing results.

\subsection{EIS Analysis}

In order to better understand the effects of co-modification on the electrode reaction process and capacity enhancement mechanism of graphite, EIS measurements were performed on the GS41 and G electrodes when the voltage is discharged to $0.8 \mathrm{~V}$ after one cycle at the current density of $0.1 \mathrm{C}$. The Nyquist plots, along with the corresponding equivalent circuit model for EIS data fitting, are presented in Figure 6. Obviously, their shapes are similar, indicating a similar reaction process, which agrees well with above galvanostatic and CV tests. However, the curve of GS41 is much smaller than that of G, indicating the impedances (including interface resistance and charge transfer reaction resistance) of GS41 is much lower than that of G. Considering the non-homogeneity such as porosity, roughness and localized distribution in the system, constant phase element $\mathrm{Q}$ is used to substitute for the capacitance $\mathrm{C}$ in the model, and Q is placed parallel to a resistor will result in a depressed semicircle (Core-Element). The intercept of the curve on the $Z^{\prime}$ axis in the high-frequency region is related to the ohmic resistance of the solution $R_{s}$, including the transportation of lithium ions and electrons through the electrolyte and the active material particles. The semicircle in the high frequency region is attributed to the solution film resistance $R_{\mathrm{f}}$ on the electrode surface, and is presented by a parallel circuit of $\mathrm{R}_{\mathrm{f}}$ and $\mathrm{Q}_{\mathrm{f}}$. The semicircle in the high-to-medium frequency range considers the diffusion and migration of lithium ions through the SEI film formed on the surface of active material, and is presented by a parallel circuit of $\mathrm{R}_{\mathrm{SEI}}$ and $\mathrm{Q}_{\mathrm{SEI}}$. The semicircles in the high and high-to-medium frequency regions are attributed to the interfacial resistance, or SEI formation, or these 
two combined dependent upon the discharge state.[36, 37] The semicircle in the medium frequency region is related to the processes of charge transfer reaction, and is presented by a parallel circuit of $R_{c t}$ and $Q_{c t}$. The oblique line in the low frequency region can be ascribed to the Warburg impedance which is regarded as the semi-infinite chemical diffusion of lithium ions in the bulk electrode.

The EIS experimental results can be fitted well with the model of $R_{s}\left(Q_{f} R_{f}\right)\left(Q_{S E I} R_{S E I}\right)\left(Q_{c t} R_{c t}\right) W$ using ZsimpWin and Z-view softwares, and the fitting parameters are summarized in Table 2. In the equivalent circuit, $\mathrm{R}_{\mathrm{s}}, \mathrm{R}_{\mathrm{f}}, \mathrm{Q}_{\mathrm{f}}, \mathrm{R}_{\mathrm{SEI}}, \mathrm{Q}_{\mathrm{SEI}}, \mathrm{R}_{\mathrm{ct}}, \mathrm{Q}_{\mathrm{ct}}$ and $\mathrm{W}$ refer to the solution Ohmic resistance (including the contributions from electrolyte, electrode, current collector, etc.), the resistance of the solution film on the electrode surface which is close to electrolyte, the double-layer capacitance of the solution film, SEI film resistance, the constant phase element of the SEI, the charge transfer reaction resistance (also known as electrochemical reaction resistance), the double-layer capacitance of the reaction interface, and the general Warburg impedance, respectively. The $\mathrm{W}$ is connected with the part of $\mathrm{R}_{\mathrm{ct}}$ and $\mathrm{Q}_{\mathrm{ct}}$ in series in the model, indicating that the diffusion and the reaction of lithium ions in the bulk electrode do not share the interface, and lithium ions diffuse to the positions where the reaction takes place. Noticeably, both materials can be fitted well with the same model, indicating that the electrode reaction process is not changed after comodification. However, the key resistances of the GS41 are much lower than that of the pristine G, and the values of $\mathrm{R}_{\mathrm{f}}, \mathrm{R}_{\mathrm{SEI}}, \mathrm{R}_{\mathrm{ct}}$, and $\mathrm{W}$ decrease $76.8 \%, 40.5 \%, 58.5 \%$ and $79.9 \%$, respectively, which further confirms that the co-modification by $\mathrm{Li}_{2} \mathrm{SiO}_{3}$ and $\mathrm{Li}_{2} \mathrm{CO}_{3}$ improves the ionic transfer properties and interface behaviors between electrode and electrolyte, as well as decreases the film resistance polarization of graphite. Therefore, the electrode reaction kinetics of graphite has been greatly improved by comodification by $\mathrm{Li}_{2} \mathrm{SiO}_{3}$ and $\mathrm{Li}_{2} \mathrm{CO}_{3}$. 


\subsection{Strain-stress analysis during cycles}

In order to real time monitor the inner pressure in the cells, non-destructive strain gauges are adopted to adhere to the surface of the cell case. According to our previous work,[27] the strain gauge installation has no influence on the electrochemical performances, so the non-destructive method can reflect the surface macroscale stress changes of lithium ion cells without affecting the electrochemical performances. As for the 2025 coin cells, the radius (R) and the thickness ( $\mathrm{t}$ ) of the SS cathode shell of the cells are $10 \mathrm{~mm}$ and $0.15 \mathrm{~mm}$, respectively. Thus the ratio of $\mathrm{t} / \mathrm{R}$ is $0.15 / 10$, much lower than 0.1 , indicating that the cathode shell can be regarded as a thin-walled plate. The material of the cell shell is 304 stainless steel whose Young's modulus $E=193 \mathrm{GPa}$ and Poisson's ratio $\mu=0.28$ at $25^{\circ} \mathrm{C}$.[38] Compared to the testing results using the same shell materials and strain gauges, the maximum strain of this test is $101 \mu \varepsilon$, lower than the our reported maximum elastic strain of $700 \mu \varepsilon$,[27] indicating that the cathode shell of the cells exhibits elastic deformation during the testing process. Therefore, the stresses at the centre of the cathode laminate can be derived using the elastic theory and the as-obtained stress-strain formula[27] is:

$$
\sigma_{\mathrm{r}}=\sigma_{\theta}=\frac{E}{1-\mu} \varepsilon_{\theta} .
$$

Where, $\sigma_{\mathrm{r}}, \sigma_{\theta}, E, \mu$, and $\varepsilon_{\theta}$, are the stress along the longitudinal direction of the cathode shell, stress along the axial direction which has an angel of $\theta$ with the longitudinal direction, Young's modulus, Poisson's ratio, and strain along the axial direction which has an angel of $\theta$ with the longitudinal direction, respectively. In order to eliminate the errors caused by the external changes of the ambient environment and the cell itself, a same cell without electrochemical tests was used as the reference cell under the same conditions. The strain values of the reference cell and the tested cell are $\varepsilon_{1}$ and $\varepsilon_{2}$, respectively, so the surface macroscopic stress $\sigma$ of the cell can be calculated as follows: 
$\sigma=\frac{E}{1-\mu}\left(\varepsilon_{2}-\varepsilon_{1}\right)$

In order to eliminate the influence of temperature changes on the strain-stress results, the stresses of the cells were real-time monitored at $25^{\circ} \mathrm{C}$. All the stress-strain tests of the cells were carried out during the above galvanostatic discharge/charge cycles at the current rate of $1.0 \mathrm{C}$. The open circuit voltage of the cells is about $1.0 \mathrm{~V}$ after activation cycles, and the stress monitored by the strain gauges is set zero at this charge state, which is also the balance point for the tests. Figure 7 shows the stress changes of the cells consisting of two materials during 50 cycles. From the stress curves during the discharge/charge processes (Figure 7 (a) and (b)), the stress increases with the increase of potential and decreases with the decrease of potential in one cycle, and a continuous increase of stress during cycles. The cyclability under the same conditions has been supplied in above Figure 4. According to the stress increasing curves after 50 cycles, calculated average stress increasing rates are supplied in Figure 7 (c) and (d). In order to evaluate the influence of ball milling and heat treatment on the stress changes of the pristine graphite, the stress changes of the GS10 cells during cycles were tested under the same conditions with that of G and GS41 samples, and the results are shown in Figure 3S. Noticeably, ball milling and heat treatment greatly increase the stress change during one cycle and declines the average stress increasing rate of the pristine graphite from 0.28 to 0.25 after 30 cycles, while co-modification with $\mathrm{Li}_{2} \mathrm{SiO}_{3}$ and $\mathrm{Li}_{2} \mathrm{CO}_{3}$ obviously decreases the stress change during one cycle and declines the average stress increasing rate of the pristine graphite from 0.28 to 0.19 after 50 cycles according to the linear fitting results. The stress change of the sample GS10 is much larger than that of the samples of G and GS41 under the same conditions, and the accumulated residue stress reaches $\sim 20 \mathrm{MPa}$ after 30 cycles, much higher than that of the sample GS41 under the same conditions. The large strain and stress may cause the fast capacity fade of GS10, as shown in Figure 4. 
Therefore, ball milling and heat treatment greatly increase the stress change of graphite, while comodification by $\mathrm{Li}_{2} \mathrm{SiO}_{3}$ and $\mathrm{Li}_{2} \mathrm{CO}_{3}$ greatly declines both the stress change and the stress increasing rate of graphite during cycles.

The stress decreases during discharge process, while increases during charge process. The stress values change from positive to negative when the stress of strain gauge changes from tension to compression, which originates from the negative deformation of the surface shell in comparison with the initial state. The graphite samples discharge firstly, during which lithium ions react with graphite and electrolyte to form lithiation products like $\mathrm{LiC}_{6}$ and SEI film on the electrode surface. Though the microscale volume will increase because of the formation of SEI film and the expansion of interlayer distance as lithium ions insert graphite interlayers during discharge process, the stress decreases, indicating that the increased volume from SEI film formation and lithium ion insertion is very limited and some other factors like electrostatic repulsion, grain size and particle size of products result in the decrease of strain. One lithium ion is positioned at the center of the carbon hexatomic ring to decrease the electrostatic repulsion between particles.[39] On the other hand, the produced lithiation products have smaller particle size and volume change than that of graphite.[40] These result in the volume shrinkage of the cell during is charge process. Because the SS cell case exhibits elastic deformation during the testing process, such shrinkage will produce a compression when the inner pressure is lower than that at the balance point, which cause the negative stress during discharge process. Such negative stress increases with the increase of discharge depth, and reaches maximum at the discharge limit voltage of $0.01 \mathrm{~V}$. On the contrary, lithium ions are extracted from the bulk structure of graphite during the charge process, and the broken SEI film and the voids between the graphite interlayers will result in the contraction of volume as lithium ions extract from graphite interlayers. However, charge using exterior energy result in the recovery of the 
graphite and lithium ion particles to increase the electrostatic repulsion between particles, and such changes produce microscale stress that further develops to macroscale stress monitored by the strain gauge, which will produce a tension when the inner pressure is higher than that at the balance point. Such tension results in the positive stress which increases linearly and reach maximum till the upper limit potential of $2.00 \mathrm{~V}$, indicating that the stress increases evenly during the whole voltage range, including the voltage platform and voltage abruptly changing area. Noticeably, the stress will not restore to previous status where the stress is zero, but higher than 0 , indicating there is a residue stress during one cycle. The decreased stress in the discharge process is lower than the increased stress in the charge process, and the residue stress increases step by step during cycles. Such residue stresses are accumulated during 50 cycles to almost form a line, as shown in Figure 7 (c) and (d). The irreversible increase in positive stack stress is from the inner tension in the cells during lithium ion insertion and extraction processes, and such residual stress will accumulate and cause the unrecoverable deformation of the cell during cycles, which would produce safety problems like swelling or bulging. Noticeably, the residue stress increases with the increase of capacity fade by considering the cyclability in Figure 4 and the stress curves in Figure 7, indicating that residue stress does harm to the cyclability. However, the co-modification by $\mathrm{Li}_{2} \mathrm{SiO}_{3}$ and $\mathrm{Li}_{2} \mathrm{CO}_{3}$ can greatly decreases the accumulated residue stress from 27.0 to $17.7 \mathrm{MPa}$ after 50 cycles under the same conditions. Such co-modification can also effectively retard the increase of residue stress, and decline the stress increasing rate of graphite from 0.28 to 0.19 .

The origin of the residue stress during cycles is very complex, including the composition, SEI film, structure or volume changes of electrode materials and electrolyte during discharge/charge cycles, side reactions of electrode materials and electrolyte, thermal effects produced during cycles, and so on. The extraction and insertion of lithium ions in graphite electrode result in $10 \%$ expansion and contraction of 
volume.[32] As for the side reactions of electrode materials and electrolyte, the process and products are also highly complex during cycles. Besides the decomposition of the $\mathrm{LiPF}_{6}$ solute in the electrolyte, the decomposition products will further react with other substances like trace water or lithium ions during discharge/charge cycles, and possible reduction mechanisms are as follows[41]

$$
\begin{aligned}
& \mathrm{LiPF}_{6} \rightarrow \mathrm{LiF}+\mathrm{PF}_{5} \uparrow \\
& \mathrm{PF}_{5}+\mathrm{H}_{2} \mathrm{O} \rightarrow 2 \mathrm{HF} \uparrow+\mathrm{POF}_{3} \\
& \mathrm{PF}_{5}+2 \mathrm{xe}^{-}+2 \mathrm{xLi}^{+} \rightarrow \mathrm{xLiF}+\mathrm{Li}_{\mathrm{x}} \mathrm{PF}_{5-\mathrm{x}} \\
& \mathrm{POF}_{3}+2 \mathrm{xe}^{-}+2 \mathrm{xLi}^{+} \rightarrow \mathrm{xLiF}+\mathrm{Li}_{\mathrm{x}} \mathrm{POF}_{3-\mathrm{x}}
\end{aligned}
$$

At the same time, the solvents of $\left(\mathrm{CH}_{2} \mathrm{O}\right)_{2} \mathrm{CO}(\mathrm{EC})$ and $\left(\mathrm{CH}_{3} \mathrm{O}\right)_{2} \mathrm{CO}(\mathrm{DMC})$ in the electrolyte will also react with lithium ions to produce sediments and gases abiding by the following reactions[42]

$$
\begin{aligned}
& 2 \mathrm{Li}^{+}+2 \mathrm{e}^{-}+2\left(\mathrm{CH}_{2} \mathrm{O}\right)_{2} \mathrm{CO} \rightarrow\left(\mathrm{CH}_{2} \mathrm{OCO}_{2} \mathrm{Li}\right)_{2} \downarrow+\mathrm{C}_{2} \mathrm{H}_{4} \uparrow \\
& 2 \mathrm{Li}^{+}+2 \mathrm{e}^{-}+\left(\mathrm{CH}_{2} \mathrm{O}\right)_{2} \mathrm{CO} \rightarrow \mathrm{Li}_{2} \mathrm{CO}_{3} \downarrow+\mathrm{C}_{2} \mathrm{H}_{4} \uparrow \\
& \mathrm{Li}^{+}+\mathrm{e}^{-}+\left(\mathrm{CH}_{3} \mathrm{O}\right)_{2} \mathrm{CO} \rightarrow \mathrm{CH}_{3} \mathrm{OCO}_{2} \mathrm{Li} \downarrow+\mathrm{CH}_{3}
\end{aligned}
$$

Therefore, SEI film and electrolyte reduction products, including $\mathrm{LiOH}, \mathrm{CH}_{2}\left(\mathrm{OCO}_{2} \mathrm{Li}\right), \mathrm{Li}_{2} \mathrm{CO}_{3}$, and $\mathrm{CH}_{3} \mathrm{OCO}_{2} \mathrm{Li}$, will depositon the electrode surface to increase the interface thickness between electrode and electrolyte, but other by-produced gases such as $\mathrm{HF}, \mathrm{C}_{2} \mathrm{H}_{4}$, will expand the cell shell to produce possible safety problems.[43, 44] Such deposits and gases will cause the irreversible expansion of cells, which may combine with the irreversible volume changes of electrode and the repeated formation and destroying of SEI film to cause residue stress during cycles. Considering the stress and impedance changes of $G$ and GS41 under the same conditions, the residue stress difference between G and GS41 is mainly from the SEI stability, interface between electrode and electrolyte, charge transfer reaction and ion diffusion. Therefore, the continuous increasing residue stress of cells may be attributed to the combination of electrode volume, 
SEI film, polymer binder, sediments and gases from the reaction of electrolyte and graphite as well as the decomposition of the electrolyte itself during cycling process.

In order to further understand the possible reasons for decreased stress andenhanced electrochemical performance by co-modification, the composition and phase structure of the sample GS41 at various charge states will be further evaluated by XRD, while the morphology will be observed by SEM.

\subsection{XRD analysis of the materials at different states of charge}

The XRD patterns of the sample GS41 at different states of charge (SOC) after the initial discharge/charge cycle at the current rate of $0.1 \mathrm{C}$ are summarized in Figure 8. Considering the low loading density of the active material, the copper current collector of the GS41 electrode was not removed for XRD characterization. To detect clearly the peaks of the samples, the XRD patterns are partially enlarged by shortening the longitudinal coordinate. Combining the standard patterns and the components, the main phases of the discharged and charged samples are attributed to graphite, $\mathrm{Li}_{2} \mathrm{SiO}_{3}$ and $\mathrm{Li}_{2} \mathrm{CO}_{3}$, without other obvious impurities. During the discharge process, the obvious peak of $\mathrm{Li}_{2} \mathrm{CO}_{3}$ in the pristine GS41 disappears, while the peaks of $\mathrm{Li}_{2} \mathrm{SiO}_{3}$ become obvious, indicating the $\mathrm{Li}_{2} \mathrm{CO}_{3}$ takes part in the formation of SEI film. During the charge process, the main peak positions of graphite and $\mathrm{Li}_{2} \mathrm{SiO}_{3}$ change little, but the peak intensities increase under the same testing conditions, indicating that the main phases have no obvious change except the unit cells and amount.The peak intensities after discharge and charge are much more obvious than that of the pristine GS41, indicating that the phase amount increases as well as the insertion and extraction of lithium ions result in the increase of the grain size according to the Scheller equation. Interestingly, the peaks of $\mathrm{Li}_{2} \mathrm{SiO}_{3}$ become obvious in spite of the small change of that of $\mathrm{Li}_{2} \mathrm{CO}_{3}$ when the sample is charged to $2.00 \mathrm{~V}$. With the extraction of lithium ions, the intensities of (101) and (004) 
peaks of graphite increase, indicating that the (101) and (004) faces grow to produce strain and stress. However, the intensities of these two peaks do not restore to the state of the pristine GS41, indicating an irreversible volume change take place in the discharge/charge cycle, which is one of the origins of residue stress, consistent with above results.

\subsection{Morphological analysis}

In order to detect the existing states of the co-modification on the surface of graphite, SEM was adopted to observe the morphological properties of the samples of G and GS41. The SEM images in Figure 9 show that the G and GS41 exhibit different particle sizes and surface morphologies. At low magnification, the pristine $\mathrm{G}$ consists of many small smoothing fragments without regular shapes, and the length of some rectangle particles is about $6 \mu \mathrm{m}$, which is not good for the adsorption and storage of electrolyte. Furthermore, such particles distribute randomly, and some smaller particles will aggregate to block the permeation of the electrolyte. After being co-modified using ball milling and heat treatment, the surface of the particles becomes rough, and some wrinkles appear besides the combination of the particles with different scales, which is beneficial for the adsorption and storage of electrolyte. Most of the particles have a wide size distribution ranging from 3 to $15 \mu \mathrm{m}$, and some small particles distribute on the surface of or among the large particles to form 3-dimensional structure for the permeation of electrolyte and the transfer of lithium ions. Furthermore, such structure is beneficial for mitigating the volume change during lithium insertion/extraction to improve the electrochemical performance,[45] and the small nanoparticles will supply plenty of reaction active sites for lithium ions to enhance the electrode reaction activity.[46] At high magnification, the $\mathrm{G}$ exhibits a dense, closed and smooth texture, while the morphology of the sample GS41 exhibits special layer features of loose graphite layers, large voids and rough surface which are in 
favor of electrolyte invasion and storage besides the increased active reaction sites. After being co-modified, the layer structure of the GS41 is much more obvious than that of the pristine graphite, suggesting that some products of $\mathrm{Li}_{2} \mathrm{SiO}_{3}$ and $\mathrm{Li}_{2} \mathrm{CO}_{3}$ may enter the interlayers of graphite. Because graphite is composed of many graphene layers, the entry of product particles is to decline the vander Waals force between graphene layers to form the sandwich structure of graphene and produced particles. The layer thickness of GS41 is less than $100 \mathrm{~nm}$, much lower than that of the pristine G, which is beneficial for the transfer of ions to enhance electrochemical performance.

\subsection{Co-modification mechanism discussions}

According to above results, co-modification by $\mathrm{Li}_{2} \mathrm{SiO}_{3}$ and $\mathrm{Li}_{2} \mathrm{CO}_{3}$ can greatly enhance the electrochemical performance and decrease the strain and stress properties of graphite by combining their advantages, and the possible mechanism for the co-modification via heating $\mathrm{Li}_{4} \mathrm{SiO}_{4}$ is supplied in Figure 10. As for the produced $\mathrm{Li}_{2} \mathrm{SiO}_{3}$, the $\mathrm{SiO}_{4}$ tetrahedra can form zigzag chains, and the unique structure means that $\mathrm{Li}_{2} \mathrm{SiO}_{3}$ has a three-dimensional path for $\mathrm{Li}^{+}$ions diffusion.[47] Thus, $\mathrm{Li}_{2} \mathrm{SiO}_{3}$ increases the $\mathrm{Li}^{+}$ ions diffusion rate to improve rate performance. At the same time, $\mathrm{Li}_{2} \mathrm{SiO}_{3}$, as a chemically inert material, has excellent structure stability in organic electrolyte, which can inhibit the by-produced HF erosion in the electrolyte.[9] Furthermore, the separated lithium metasilicate in or between the graphite layers prevents the collapse of the graphite layers during lithium ion insertion and extraction process for reducing the volume change of electrode. The formed sandwich structure of graphene and modified particles is beneficial for the conductivity and ionic diffusion of graphite electrode. $\mathrm{Li}_{2} \mathrm{SiO}_{3}$ also enhances the electronic conductivity of electrode materials to decrease the polarization.[19] On the other hand, the presence of $\mathrm{Li}_{2} \mathrm{CO}_{3}$ in electrolytes favors the formation of more compact and conductive SEI film. As a 
result, the initial irreversibility and its related gas generation are significantly limited,[48, 49] agreeing well with above testing results. The combination of $\mathrm{Li}_{2} \mathrm{SiO}_{3}$ and $\mathrm{Li}_{2} \mathrm{CO}_{3}$ improves the electrode reaction kinetic properties and SEI film quality as well as limits the swelling of graphite electrode during cycles, which results in the increase of electrochemical performance and the decrease of stress-strain properties.

\section{Conclusions}

The co-modified graphite samples were in situ synthesized facilely by the novel method of ball milling and heating the precursor mixture of $\mathrm{Li}_{4} \mathrm{SiO}_{4}$ and graphite in an inert atmosphere. Ball milling and heat treatment are not good for enhancing the rate performance and cyclability as well as decreasing the strain properties of graphite. Combination of $\mathrm{Li}_{2} \mathrm{SiO}_{3}$ and $\mathrm{Li}_{2} \mathrm{CO}_{3}$ enhances the electrochemical performance of graphite, while $\mathrm{Li}_{4} \mathrm{SiO}_{4}$ residue declines the electrochemical performance of the co-modified graphite in spite of the better performance than that of the pristine graphite. As the mass ratio of graphite to $\mathrm{Li}_{4} \mathrm{SiO}_{4}$ is 4:1, the as-obtained co-modified graphite has only $\mathrm{Li}_{2} \mathrm{SiO}_{3}$ and $\mathrm{Li}_{2} \mathrm{CO}_{3}$, and exhibits the best electrochemical performance. The initial reversible capacities are respectively 371, 357, 334, and $285 \mathrm{mAh}$ $\mathrm{g}^{-1}$ at the current rates of $0.1,1.0,2.0$, and $5.0 \mathrm{C}$, and the capacity maintenance ratios are respectively $96.2 \%, 90.0 \%$, and $76.8 \%$ of the initial reversible capacities after 50 cycles at the current rates of 1.0, 2.0, and 5.0 C. $\mathrm{CV}$ and EIS results further demonstrate that co-modification by $\mathrm{Li}_{2} \mathrm{SiO}_{3}$ and $\mathrm{Li}_{2} \mathrm{CO}_{3}$ does not change the electrode reaction process, but declines the polarization degree and charge transfer reaction and diffusion impedances of the pristine graphite. Strain-stress results show that such co-modification retards and hinders the increase of the cell surface macroscale stress during cycles, and the residue stress values of the co-modified graphite and pristine graphite reach17.7 and 27.0 $\mathrm{MPa}$ after 50cycles at the current rate of 1.0 C, respectively. Such residue stress increases during cycles, synchronizing with the capacity fade. The 
possible co-modification mechanisms are discussed.

Co-modification by $\mathrm{Li}_{2} \mathrm{SiO}_{3}$ and $\mathrm{Li}_{2} \mathrm{CO}_{3}$, combining the advantages of respective materials, greatly enhance the electrochemical performance and decrease the surface macroscale stress of graphite lithium cells, which is highly significant for the extensive applications and safety management of current batteries. In a sealed battery, the inner pressure is superior to the surface temperature to cause the safety problems like swelling, leakage, and explosion and burning, so it is anticipated to control such hazards by monitoring the stress and combining with other techniques like blocking, cutting, ending, injecting chemicals, and so on. The novel method to in situ prepare co-modified graphite using $\mathrm{Li}_{4} \mathrm{SiO}_{4}$ precursor, eliminating the shortcomings of poor dispersion of powders and poor solubility of $\mathrm{Li}_{2} \mathrm{CO}_{3}$ in organic electrolyte, might also be applicable for ameliorating the electrochemical performance and safety properties of other electrode materials for high performance batteries. Furthermore, the non-destructive strain-stress method may be an effective way to monitor the strain and stress changes and take precautions against the safety problems of current batteries, which is much more accurate than current temperature monitoring for safety management and sustainable development.

\section{Acknowledgments}

We gratefully acknowledge the financial support from the National Science Foundation of China (Grant No. 21206099 and 21576170), the Experimental Technical Project (2015-0141), and Chemical Engineering Star funding of Sichuan University. 


\section{Tables}

Table $1 \mathrm{E}_{\mathrm{O}}, \mathrm{E}_{\mathrm{R}}, \Delta \mathrm{E}, \mathrm{i}_{\mathrm{O}}$ and $\mathrm{i}_{\mathrm{R}}$ of the $\mathrm{G}$ and GS41 cells at different scanning rates.

\begin{tabular}{|c|c|c|c|c|c|c|}
\hline $\begin{array}{l}\text { Scanning rate } \\
(\mathrm{mV} / \mathrm{s})\end{array}$ & Sample & $\mathrm{E}_{\mathrm{O}}(\mathrm{V})$ & $\mathrm{E}_{\mathrm{R}}(\mathrm{V})$ & $\Delta \mathrm{E}(\mathrm{V})$ & $\mathrm{i}_{\mathrm{O}}\left(\mathrm{mA} / \mathrm{cm}^{2}\right)$ & $\mathrm{i}_{\mathrm{R}}\left(\mathrm{mA} / \mathrm{cm}^{2}\right)$ \\
\hline \multirow{2}{*}{0.1} & $\mathrm{G}$ & 0.2 & 0.17 & 0.06 & 4.06 & -1.43 \\
\hline & $\overline{\mathrm{GS} 41}$ & 0.21 & 0.17 & 0.04 & 4.19 & -1.40 \\
\hline \multirow{2}{*}{0.2} & $\mathrm{G}$ & 0.25 & 0.13 & 0.12 & 5.40 & -2.40 \\
\hline & $\overline{\text { GS41 }}$ & 0.24 & 0.16 & 0.08 & 5.64 & -2.29 \\
\hline \multirow{2}{*}{0.5} & $\mathrm{G}$ & 0.29 & 0.12 & 0.17 & 7.60 & -4.60 \\
\hline & $\overline{\mathrm{GS}} 41$ & 0.28 & 0.15 & 0.13 & 8.27 & -4.32 \\
\hline \multirow{2}{*}{1.0} & $\mathrm{G}$ & 0.31 & I & I & 8.82 & I \\
\hline & $\overline{\text { GS41 }}$ & 0.30 & I & / & 9.63 & I \\
\hline \multirow{2}{*}{2.0} & $\mathrm{G}$ & 0.39 & I & I & 1.12 & I \\
\hline & $\overline{\text { GS41 }}$ & 0.35 & I & I & 1.21 & I \\
\hline
\end{tabular}


Table $2 \mathrm{R}_{\mathrm{s}}, \mathrm{R}_{\mathrm{f}}, \mathrm{R}_{\mathrm{SEI}}, \mathrm{R}_{\mathrm{ct}}$ and $\mathrm{W}$ of the $\mathrm{G}$ and GS41 cells.

\begin{tabular}{cccccc}
\hline Sample & $R_{s}\left(\mathrm{ohm} / \mathrm{cm}^{2}\right)$ & $R_{f}\left(\mathrm{ohm} / \mathrm{cm}^{2}\right)$ & $R_{\mathrm{SEI}}\left(\mathrm{ohm} / \mathrm{cm}^{2}\right)$ & $R_{\mathrm{ct}}\left(\mathrm{ohm} / \mathrm{cm}^{2}\right)$ & $W \times 10^{-3}\left(\mathrm{ohm} / \mathrm{cm}^{2}\right)$ \\
\hline $\mathrm{G}$ & 1.8 & 48.3 & 41.0 & 6.6 & 5.5 \\
GS41 & 3.0 & 11.2 & 24.4 & 2.7 & 1.3 \\
\hline
\end{tabular}




\section{References}

[1] Y. Xue, J. Deng, C. Wang, R.G. Mendes, L. Chen, Y. Xiao, Q. Zhang, T. Zhang, X. Hu, X. Li, A pinecone-inspired nanostructure design for long-cycle and high performance Si anodes, Journal of Materials Chemistry A, 15 (2016) 5395-5401.

[2] S.H. Park, H.J. Kim, J. Lee, Y.K. Jeong, J.W. Choi, H. Lee, Mussel-inspired polydopamine-coating for enhanced thermal stability and rate performance of graphite anodes in Li-ion batteries, ACS Applied Materials \& Interfaces, 8 (2016) 13973-13981.

[3] Y.H. Li, M.L. Lee, F.M. Wang, et al, Electrochemical performance and safety features of high-safety lithium ion battery using novel branched additive for internal short protection, Applied Surface Science,261 (2012) 306-311.

[4] H. Wang, S. Simunovic, H. Maleki, J.N. Howard, J.A. Hallmark, Internal configuration of prismatic lithium-ion cells at the onset of mechanically induced short circuit, Journal of Power Sources, 306 (2016) 424-430.

[5] M. Xiao, X.S. Du, et al, The influence of thermal treatment conditions on the structures and electrical conductivities of graphite oxide, New Carbon Materials, 19 (2004) 92-96.

[6] D. Shanmukaraj, S. Grugeon, S. Laruelle, M. Armand, Hindered Glymes for Graphite-Compatible Electrolytes, Chemsuschem, 8 (2015) 353-360.

[7] J. Shim, K.A. Striebel, Electrochemical characterization of thermally oxidized natural graphite anodes in lithium-ion batteries, Journal of Power Sources, 164 (2007) 862-867.

[8] Y.S. Wu, Y.H. Lee, Z.W. Yang, Z.Z. Guo, H.C. Wu, Influences of surface fluorination and carbon coating with furan resin in natural graphite as anode in lithium-ion batteries, Journal of Physics \& Chemistry of Solids, 69 (2008) 376-382. [9] E. Zhao, X. Liu, H. Zhao, X. Xiao, Z. Hu, Ion conducting $\mathrm{Li}_{2} \mathrm{SiO}_{3}$-coated lithium-rich layered oxide exhibiting high rate capability and low polarization, Chemical Communications, 51 (2015) 9093-9096.

[10] K.L. Lee, J.Y. Jung, S.W. Lee, H.S. Moon, J.W. Park, Electrochemical characteristics of a-Si thin film anode for Liion rechargeable batteries, Journal of Power Sources, 129 (2004) 270-274.

[11] M. Halim, Phenyl-rich silicone oil as a precursor for $\mathrm{SiO} / \mathrm{C}$ anode materials for long-cycle and high-rate lithium ion batteries, Journal of Materials Chemistry A, 4 (2016) 2651-2656.

[12] N. Delpuech, N. Dupre, P. Moreau, J.S. Bridel, J. Gaubicher, B. Lestriez, D. Guyomard, Mechanism of silicon electrode aging upon cycling in full lithium-ion batteries, ChemSusChem, 8 (2016) 841-848.

[13] S.Y. Kim, J. Lee, B.H. Kim, Y.J. Kim, K.S. Yang, M.S. Park, A facile synthesis of carbon-coated silicon/graphite spherical composites for high-performance lithium-ion batteries, ACS Applied Materials \& Interfaces, 8 (2016) 1336013372.

[14] X.H. Liu, L. Zhong, S. Huang, S.X. Mao, T. Zhu, J.Y. Huang, Size-dependent fracture of silicon nanoparticles during lithiation, ACS Nano, 6 (2012) 1522-1531.

[15] L. Luo, Y. Xu, H. Zhang, X. Han, H. Dong, X. Xu, C. Chen, Y. Zhang, J. Lin, A comprehensive understanding on the high polar polyacrylonitrile as an effective binder for Li-ion battery nano-Si anodes, ACS Applied Materials \& Interfaces, 8 (2016) 8154-8161. 
[16] Z.W. Zhou, Y.T. Liu, X.M. Xie, X.Y. Ye, Constructing Novel Si/SnO ${ }_{2}$ core-shell heterostructures by facile selfassembly of $\mathrm{SnO}_{2}$ nanowires on silicon hollow nanospheres for large, reversible lithium storage, ACS Applied Materials \& Interfaces, 8 (2016) 7092-7100.

[17] X. Zhao, X. Rui, W.W. Zhou, L. Tan, Q. Yan, Z. Lu, H.H. Hng, Growth of Si nanowires in porous carbon with enhanced cycling stability for Li-ion storage, Journal of Power Sources, 250 (2014) 160-165.

[18] X. Wu, Z.Q. Shi, C.Y. Wang, J. Jin, Nanostructured $\mathrm{SiO}_{2} / \mathrm{C}$ composites prepared via electrospinning and their electrochemical properties for lithium ion batteries, Journal of Electroanalytical Chemistry, 746 (2015) 62-67.

[19] J. Bai, Z. Gong, D. Lv, Y. Li, H. Zou, Y. Yang, Nanostructured $0.8 \mathrm{Li}_{2} \mathrm{FeSiO}_{4} / 0.4 \mathrm{Li}_{2} \mathrm{SiO}_{3} / \mathrm{C}$ composite cathode material with enhanced electrochemical performance for lithium-ion batteries, J. Mater. Chem, 22 (2012) 12128-12132.

[20] S.S. Zhang, K. Xu, T.R. Jow, Effect of $\mathrm{Li}_{2} \mathrm{CO}_{3}$-coating on the performance of natural graphite in Li-ion battery, Electrochemistry Communications, 5 (2003) 979-982.

[21] A. Khorassani, A.R. West, $\mathrm{Li}^{+}$ion conductivity in the system $\mathrm{Li}_{4} \mathrm{SiO}_{4} / \mathrm{Li}_{3} \mathrm{VO}_{4}$, Journal of Solid State Chemistry, 53 (1984) 369-375.

[22] B.Y. Yin, K. Niu, Preparation Process of $\mathrm{Li}_{4} \mathrm{SiO}_{4}$ Pebbles as Tritium Breeding Materials, Yuanzineng Kexue Jishu/atomic Energy Science \& Technology, 45 (2011) 73-79.

[23] J. Wen, Y. Yu, C. Chen, A review on lithium-ion batteries safety issues: existing problems and possible solutions, Materials Express, 2 (2012) 197-212.

[24] J. Cannarella, C.B. Arnold, Stress evolution and capacity fade in constrained lithium-ion pouch cells, Journal of Power Sources, 245 (2014) 745-751.

[25] V.A. Sethuraman, N.V. Winkle, D.P. Abraham, A.F. Bower, P.R. Guduru, Real-time stress measurements in lithiumion battery negative-electrodes, Journal of Power Sources, 206 (2012) 334-342.

[26] S. Renganathan, G. Sikha, R.E. White, Stress Analysis in Lithium Intercalation Electrodes, J. Electrochem Soc, 157 (2009) 155-163.

[27] S.Zhou, G.X. Wang, Y. Xiao, Q. Li, D. Yang, K.P. Yan, Influence of charge status on the stress safety properties of $\mathrm{Li}\left(\mathrm{Ni}_{1 / 3} \mathrm{Co}_{1 / 3} \mathrm{Mn}_{1 / 3}\right) \mathrm{O}_{2}$ cells, RSC Advances, 6 (2016) 63378-663389.

[28] Y. Gong, X. Yu, M. Yang, J. Wei, Y. Shi, Z. Huang, T. Lu, W. Huang, A facile approach to fabricate $\mathrm{Li}_{4} \mathrm{SiO}_{4}$ ceramic pebbles as tritium breeding materials, Materials Letters, 159 (2015) 245-248.

[29] G. Wang, R. Liu, M. Chen, H. Kang, X. Li, K. Yan, A novel synthesis of spherical LiFePO 4 /C composite using Fe 1.5 P and mixed lithium salts via oxygen permeation, Korean Journal of Chemical Engineering, 29 (2012) $1094-1101$.

[30] G.X. Wang, K.P. Yan, Z. Yu, M. Qu, Facile synthesis and high rate capability of $\mathrm{Li}_{4} \mathrm{Ti}_{5} \mathrm{O}_{12} / \mathrm{C}$ composite materials with controllable carbon content, Journal of Applied Electrochemistry, 40 (2010) 821-831.

[31] B. Liu, Y. Zhou, D. Jia, P. Zuo, Y. Shao, J. Zhang, Effect of heat treatment temperature on microstructure and electrochemical properties of hollow carbon spheres prepared in high-pressure argon, Bulletin of Materials Science, 34 (2011) 1707-1714.

[32] M.E. Spahr, H. Wilhelm, F. Joho, J.C. Panitz, J. Wambach, P. Novák, N. Dupont-Pavlovsky, Purely Hexagonal Graphite and the Influence of Surface Modifications on Its Electrochemical Lithium Insertion Properties, Vida Rural, 
149 (2002) 74-76.

[33] D.C.C. Silva, O. Crosnier, G. Ouvrard, J. Greedan, A. Safa-Sefat, L.F. Nazar, Reversible lithium uptake by FeP2, Electrochemical and Solid-State Letters, 6 (2003) A162-A165.

[34] G.X. Wang, R. Zhang, T. Jiang, N.A. Chernova, Z. Dong, M.S. Whittingham, Facile synthesis and electrochemical performance of the nanoscaled FeP y anode, Journal of Power Sources, 270 (2014) 248-256.

[35] F. Huang, Q. Zhao, C. Luo, G. Wang, K. Yan, D. Luo, Influence of $\mathrm{Cr}^{3+}$ concentration on the electrochemical behavior of the anolyte for vanadium redox flow batteries, Chinese Science Bulletin, 57 (2012) 4237-4243.

[36] J. Guo, A. Sun, X. Chen, C. Wang, A. Manivannan, Cyclability study of silicon-carbon composite anodes for lithium-ion batteries using electrochemical impedance spectroscopy, Electrochimica Acta, 56 (2011) 3981-3987.

[37] M. Gaberscek, J. Moskon, B. Erjavec, R. Dominko, J. Jamnik, The importance of interphase contacts in Li ion electrodes: the meaning of the high-frequency impedance arc, Electrochemical and Solid-State Letters, 11 (2008) 170174.

[38] H. Kim, J.Y. Kang, D. Son, D.S. Lee, T.H. Lee, W.C. Jeong, K.M. Cho, Microstructures and mechanical properties of cold-work tool steels: a comparison of $8 \% \mathrm{Cr}$ steel with STD11, Journal of the Korean Society for Heat Treatment, 27 (2014) 242-252.

[39] Z. Zimpel, B.R. Nelson, J.A. Weil, SCF-MO computational analysis of the geometric conformation and charge, Canadian Journal of Chemistry, 74 (2011) 70-78.

[40] Y. Soo, S. M. Lee, Effects of particle size on the thermal stability of lithiated graphite anode, Electrochimica Acta, 12 (2009) 3339-3343.

[41] P. Arora, R.E. White, M. Doyle, Capacity Fade Mechanisms and Side Reactions in Lithium-Ion Batteries, Journal of the Electrochemical Society, 145 (1998) 3647-3667.

[42] N. Gang, B. Haran, B.N. Popov, Capacity fade study of lithium-ion batteries cycled at high discharge rates, Journal of Power Sources, 117 (2003) 160-169.

[43] K.B. Chang, R.Z. Yin, S.J. Shin, Y.S. Lee, W. Choi, Y.S. Kim, Electrochemical properties and gas evolution behavior of overlithiated $\mathrm{Li}_{2} \mathrm{NiO}_{2}$ as cathode active mass for rechargeable $\mathrm{Li}$ ion batteries, Journal of the Electrochemical Society, 159 (2012) A887-A893.

[44] L.J. Fu, K. Endo, K. Sekine, T. Takamura, Y.P. Wu, H.Q. Wu, Studies on capacity fading mechanism of graphite anode for Li-ion battery, Journal of Power Sources, 162 (2006) 663-666.

[45] K.M. Gyu, C. Jaephil, Reversible and high-capacity nanostructured electrode materials for li-ion batteries, Advanced Functional Materials, 19 (2009) 1497-1514.

[46] H. Kang, G. Wang, H. Guo, M. Chen, C. Luo, K. Yan, Facile synthesis and electrochemical performance of $\mathrm{LiFePO}_{4} / \mathrm{C}$ composites using Fe-P waste slag, Industrial \& Engineering Chemistry Research, 51 (2012) 7923-7931.

[47] I.D. Raistrick, C. Ho, R.A. Huggins, I.D. Raistrick, C. Ho, Ionic conductivity of some lithium silicates and aluminosilicates, Journal of the Electrochemical Society, 123 (1976) 1469-1476.

[48] Y.K. Choi, K.I. Chung, W.S. Kim, Y.E. Sung, S.M. Park, Suppressive effect of $\mathrm{Li}_{2} \mathrm{CO}_{3}$ on initial irreversibility at carbon anode in Li-ion batteries, Journal of Power Sources, 104 (2002) 132-139. 
[49] J.S. Shin, C.H. Han, U.H. Jung, S.I. Lee, H.J. Kim, K. Kim, Effect of $\mathrm{Li}_{2} \mathrm{CO}_{3}$ additive on gas generation in lithiumion batteries, Journal of Power Sources, 109 (2002) 47-52. 


\section{Figure captions}

Figure 1 Stress-strain and electrochemical testing system.

Figure 2 XRD patterns of the samples of G, GS51, GS41, and GS31.

Figure 3 Typical galvanostatic discharge/charge curves of the samples of G, GS51, GS41, and GS31 at different current rates.

Figure 4 Cycling performance (a), and retention ratios of capacity (b) of G, GS51, GS41, and GS31 at different current rates.

Figure 5 Cyclic voltammograms of G and GS41 at different scanning rates.

Figure 6 EIS curves and the corresponding fitting model of G and GS41.

Figure 7 Stress changes of G and GS41 during cycles.

Figure 8 XRD patterns of GS41under different charge states.

Figure 9 SEM images of the samples of $G(a, c)$ and GS41 (b, d).

Figure 10 Schematic diagram of the graphite co-modified by $\mathrm{Li}_{2} \mathrm{SiO}_{3}$ and $\mathrm{Li}_{2} \mathrm{CO}_{3}$ via heating $\mathrm{Li}_{4} \mathrm{SiO}_{4}$. 
Figures

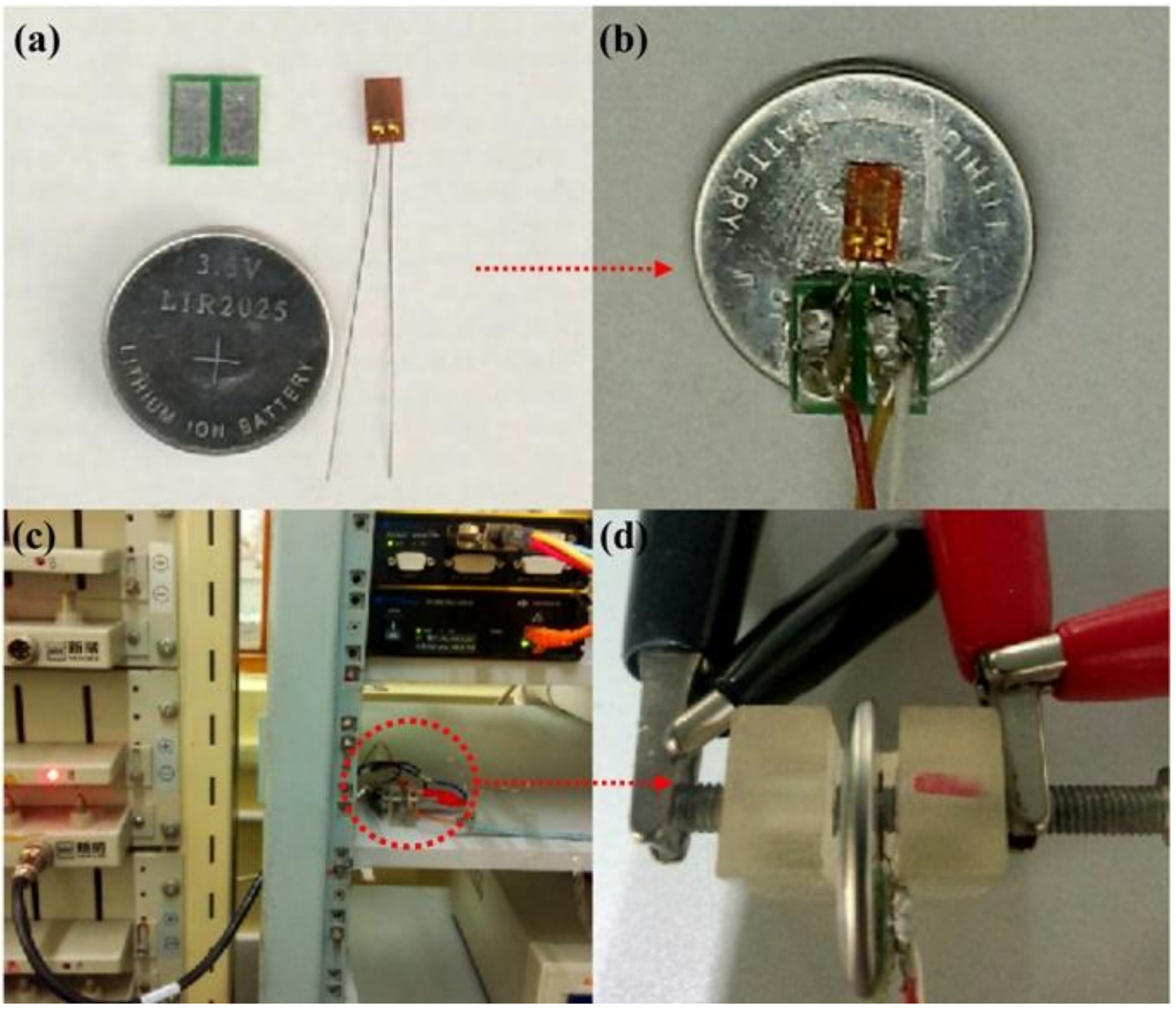

Figure 1 


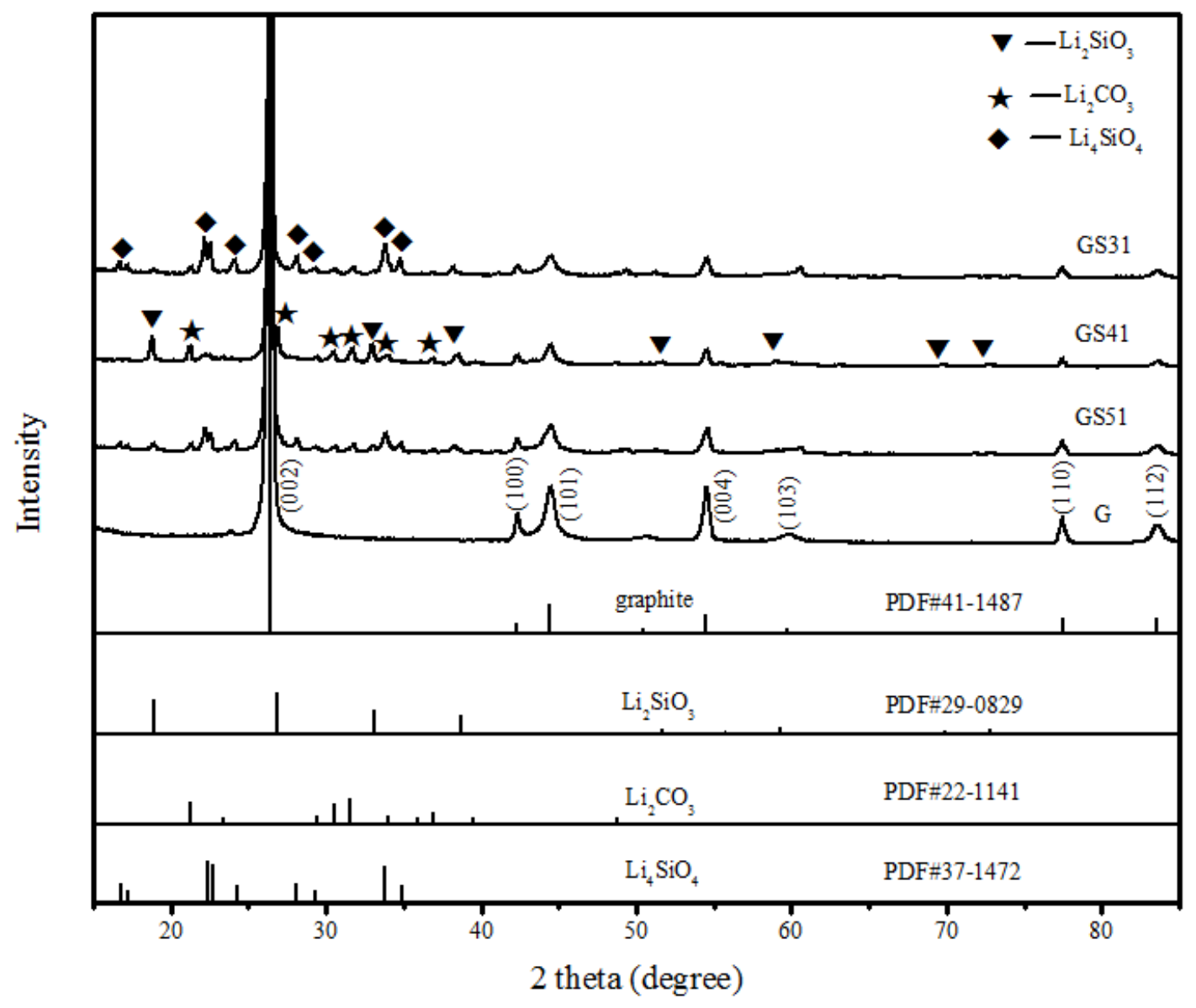

Figure 2 

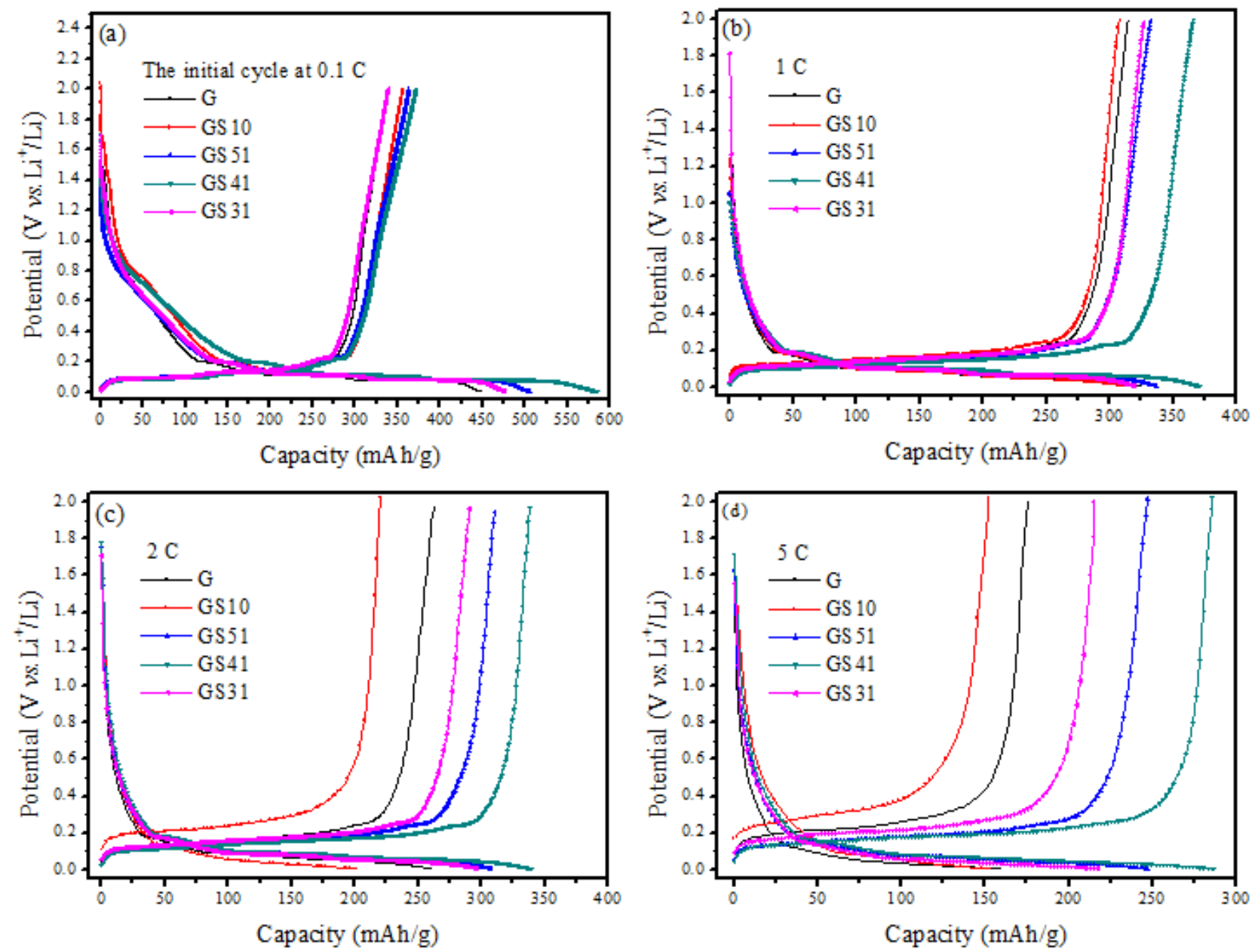

Figure 3 

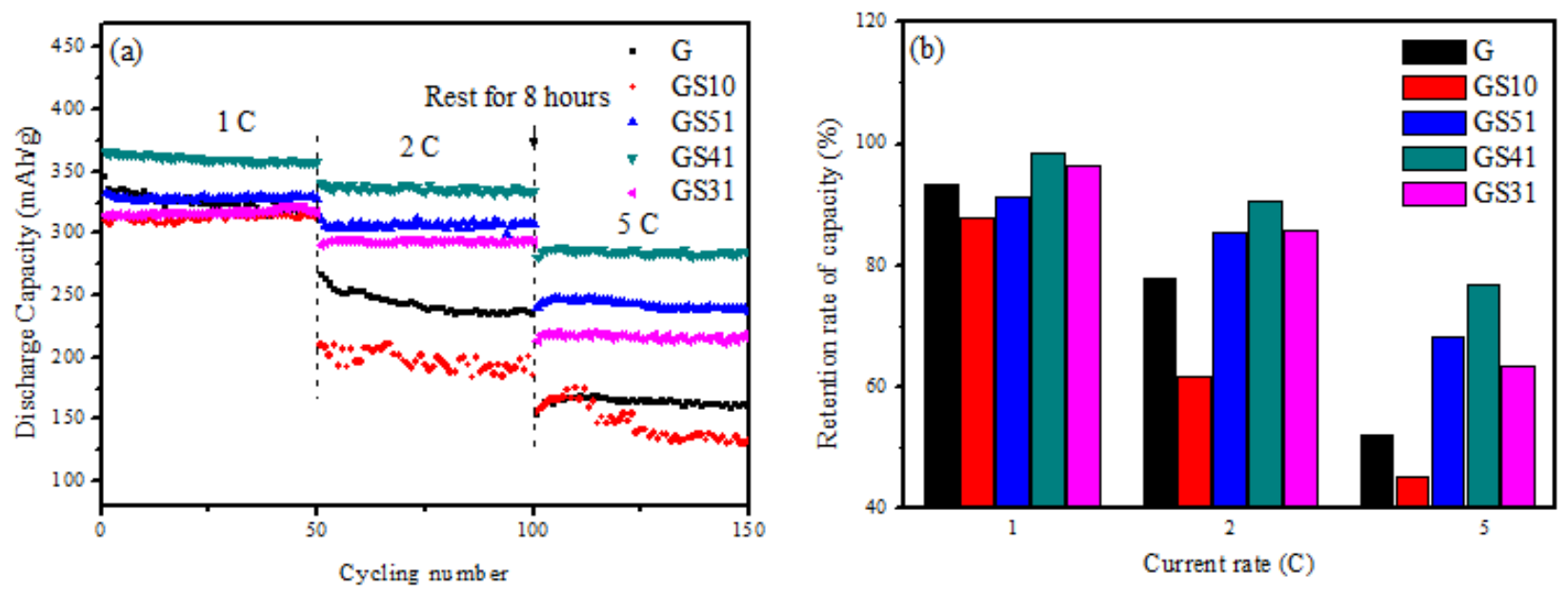

Figure 4 

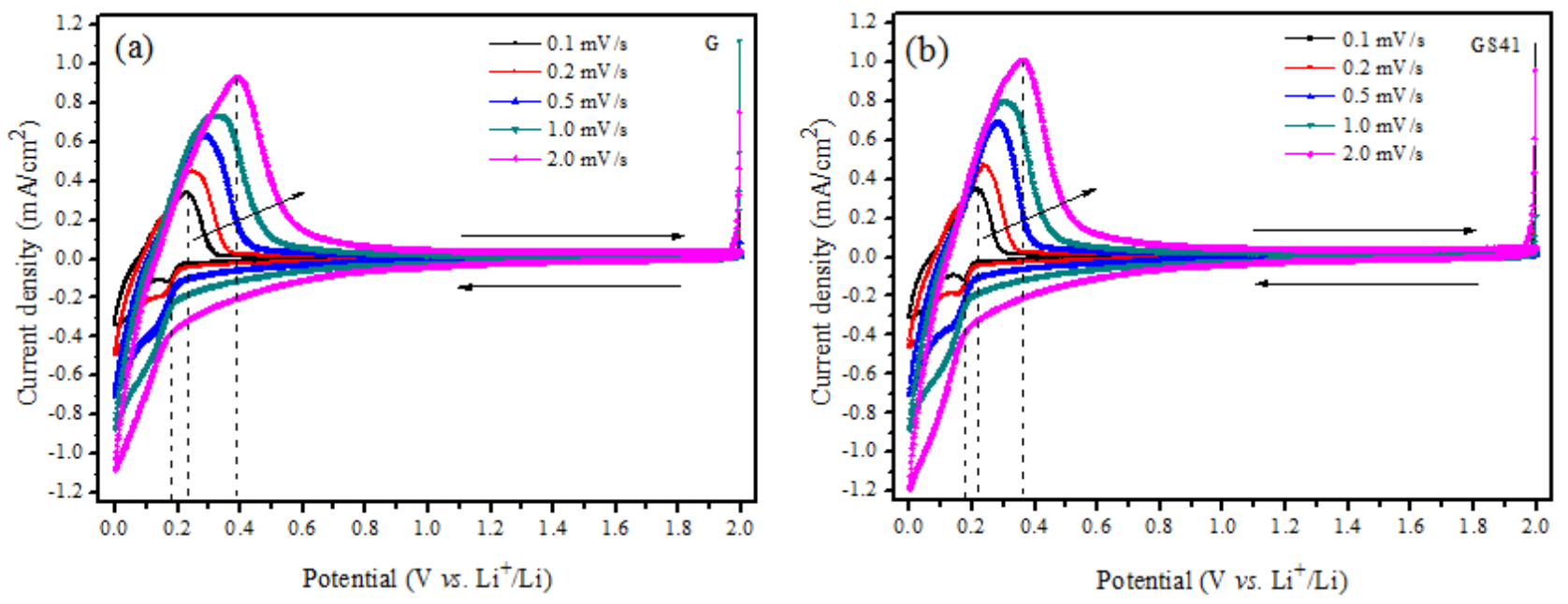

Figure 5 


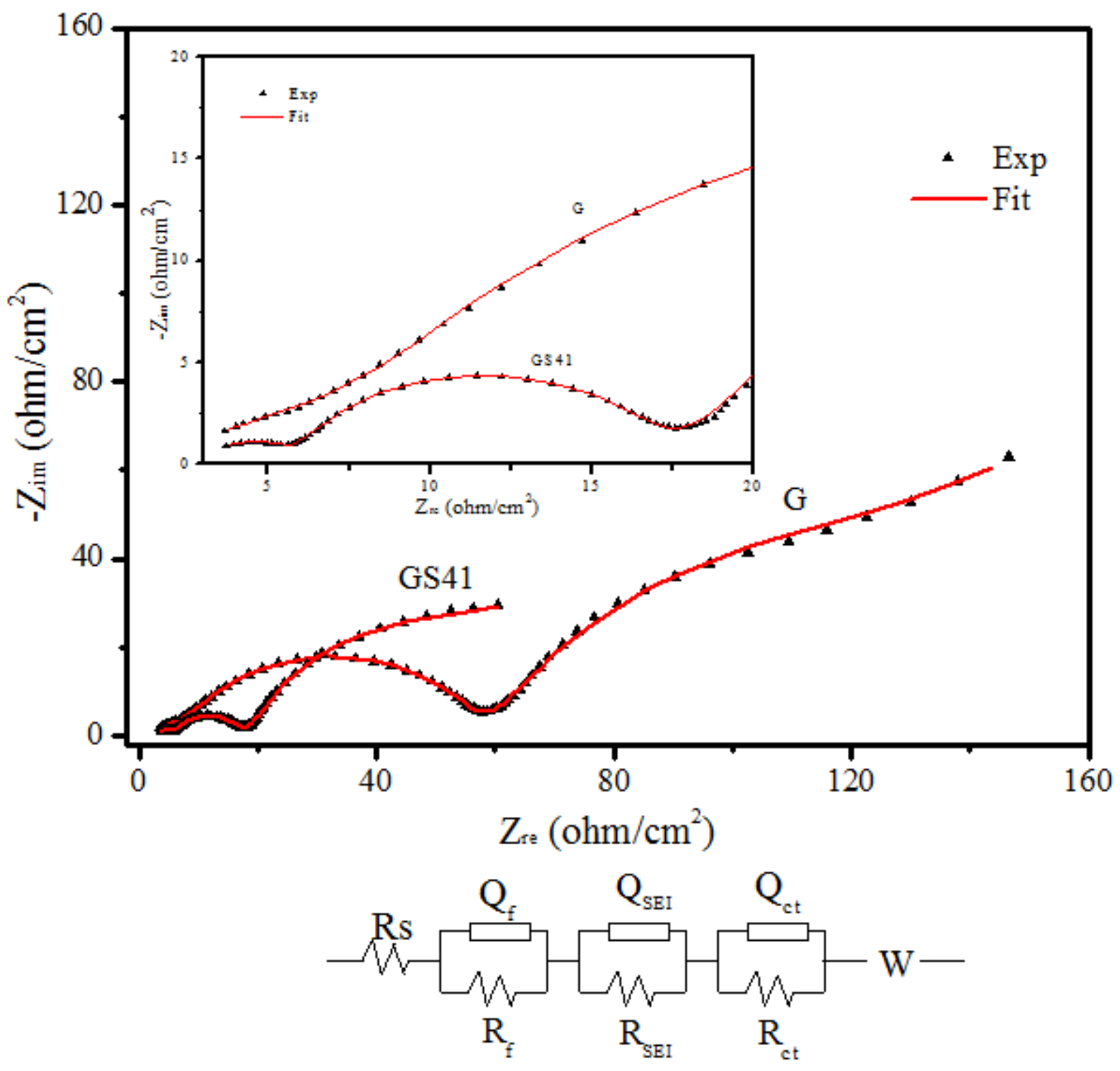

Figure 6 

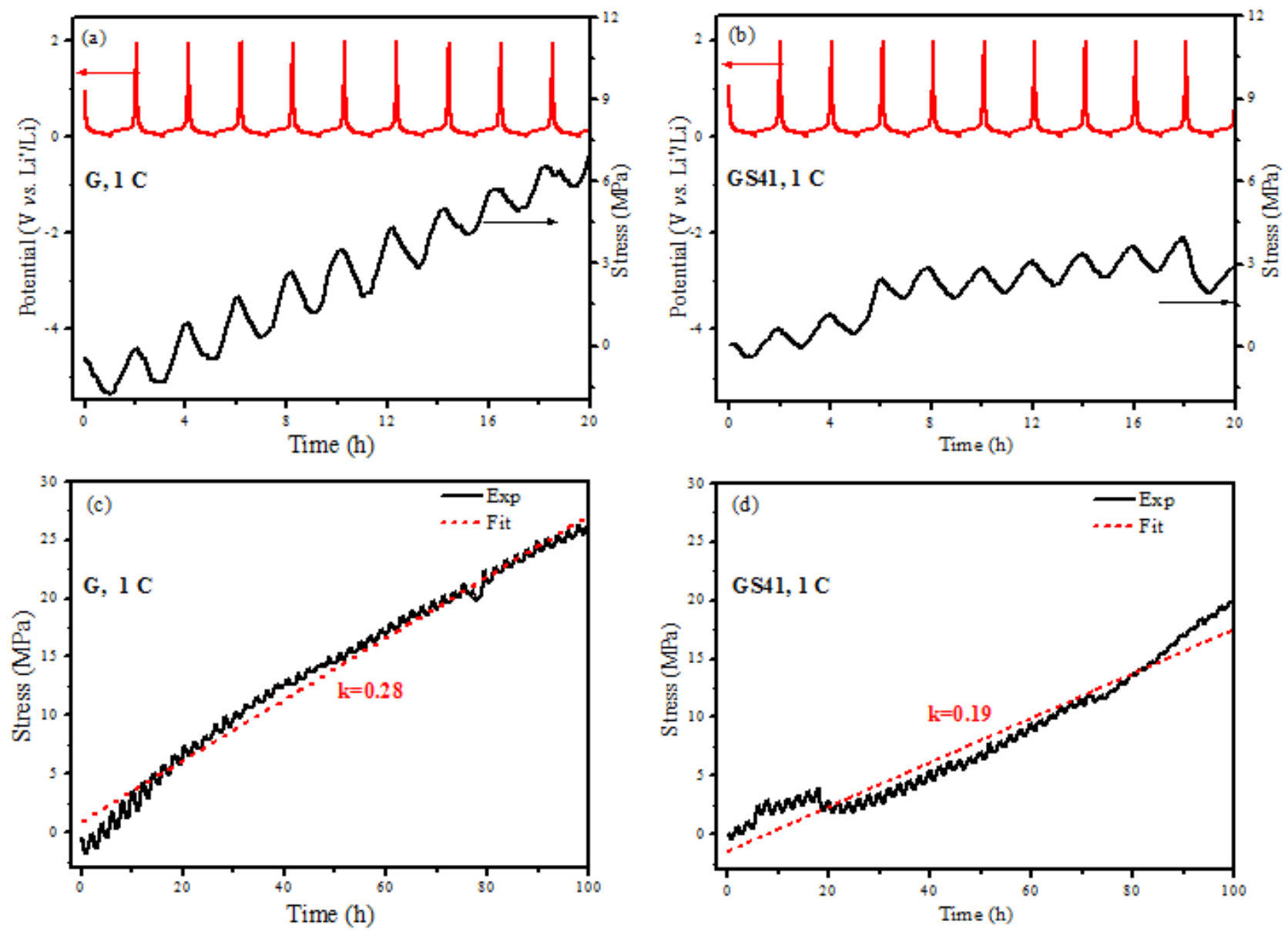

Figure 7 


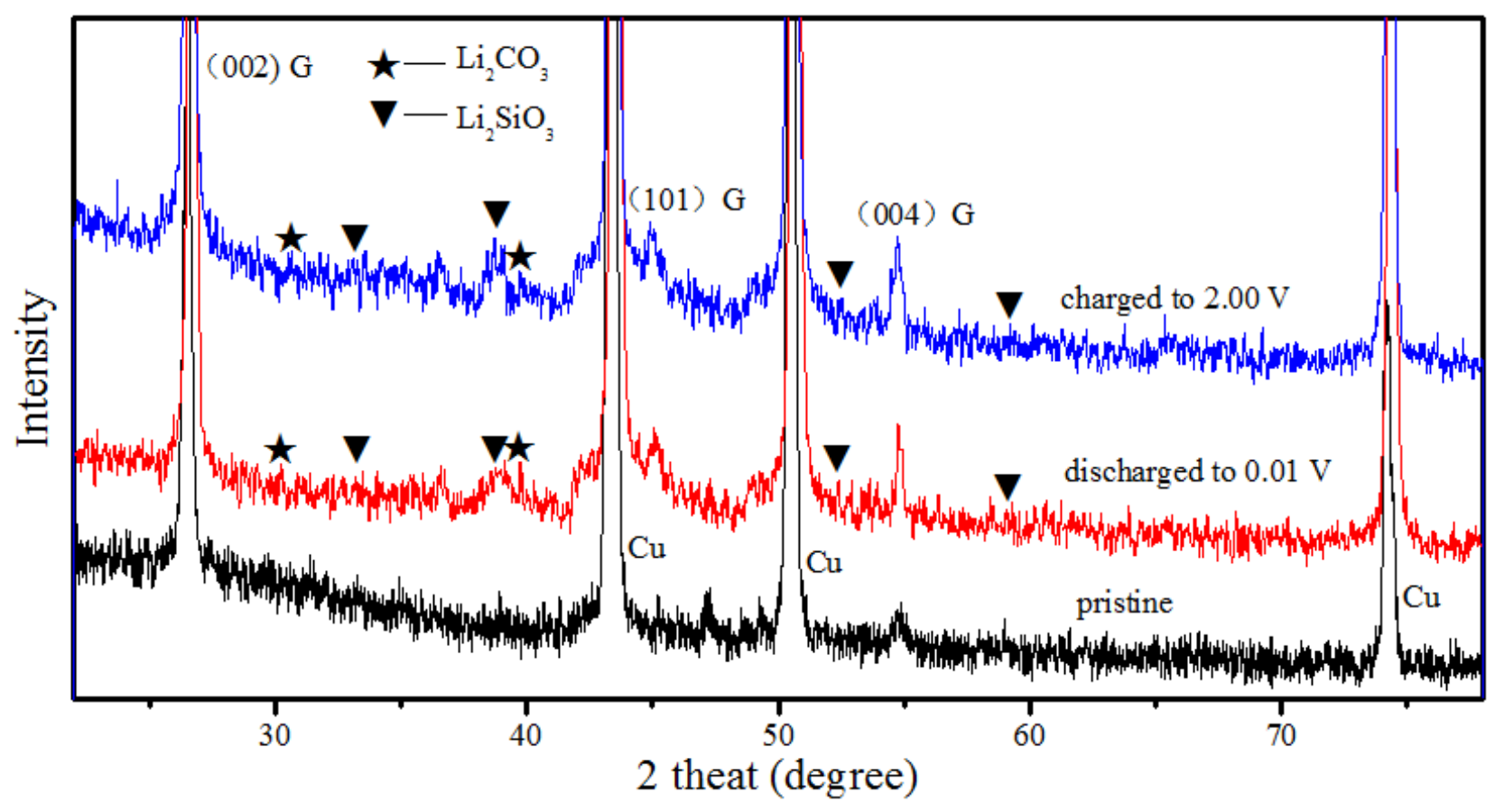

Figure 8 

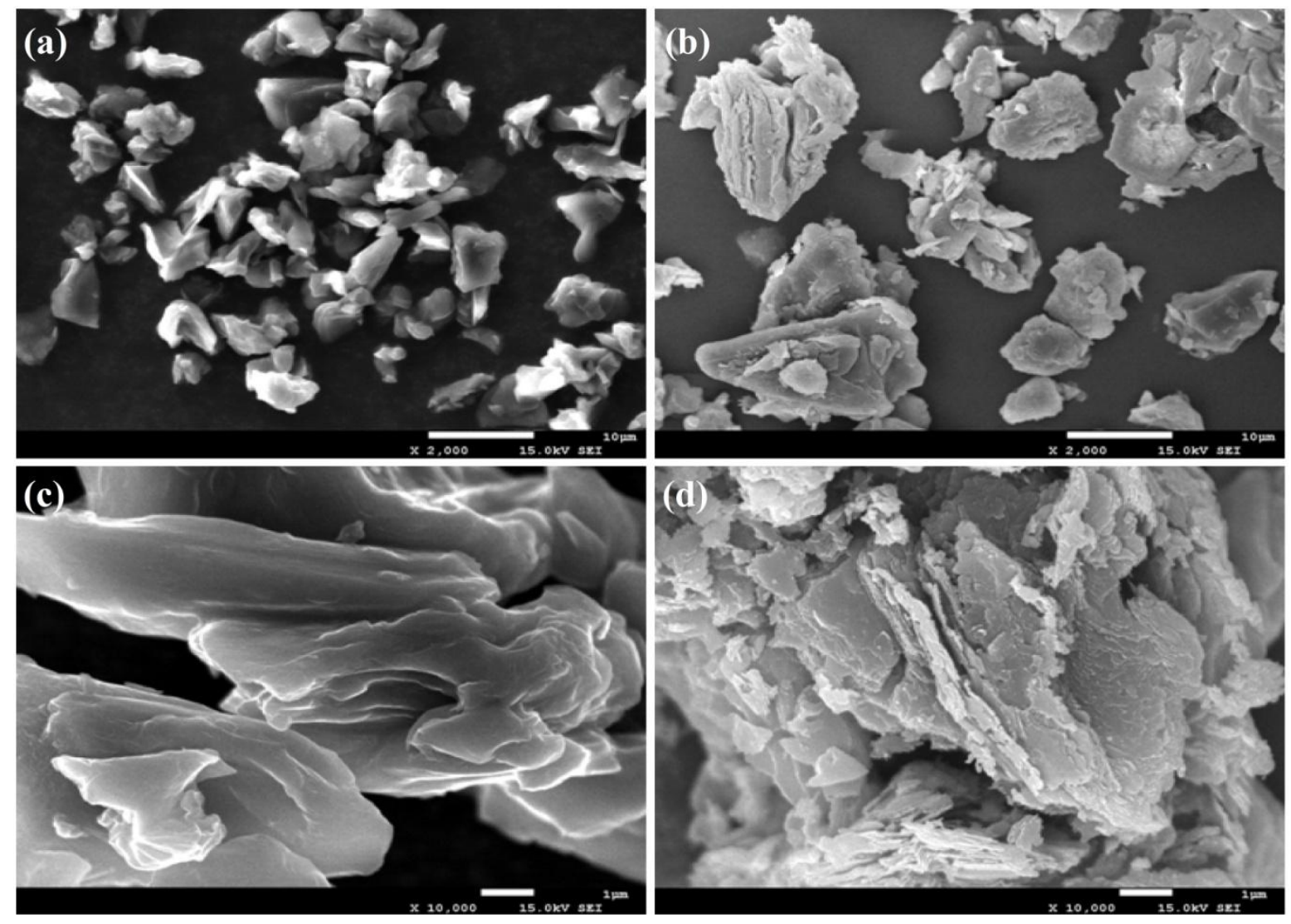

Figure 9 


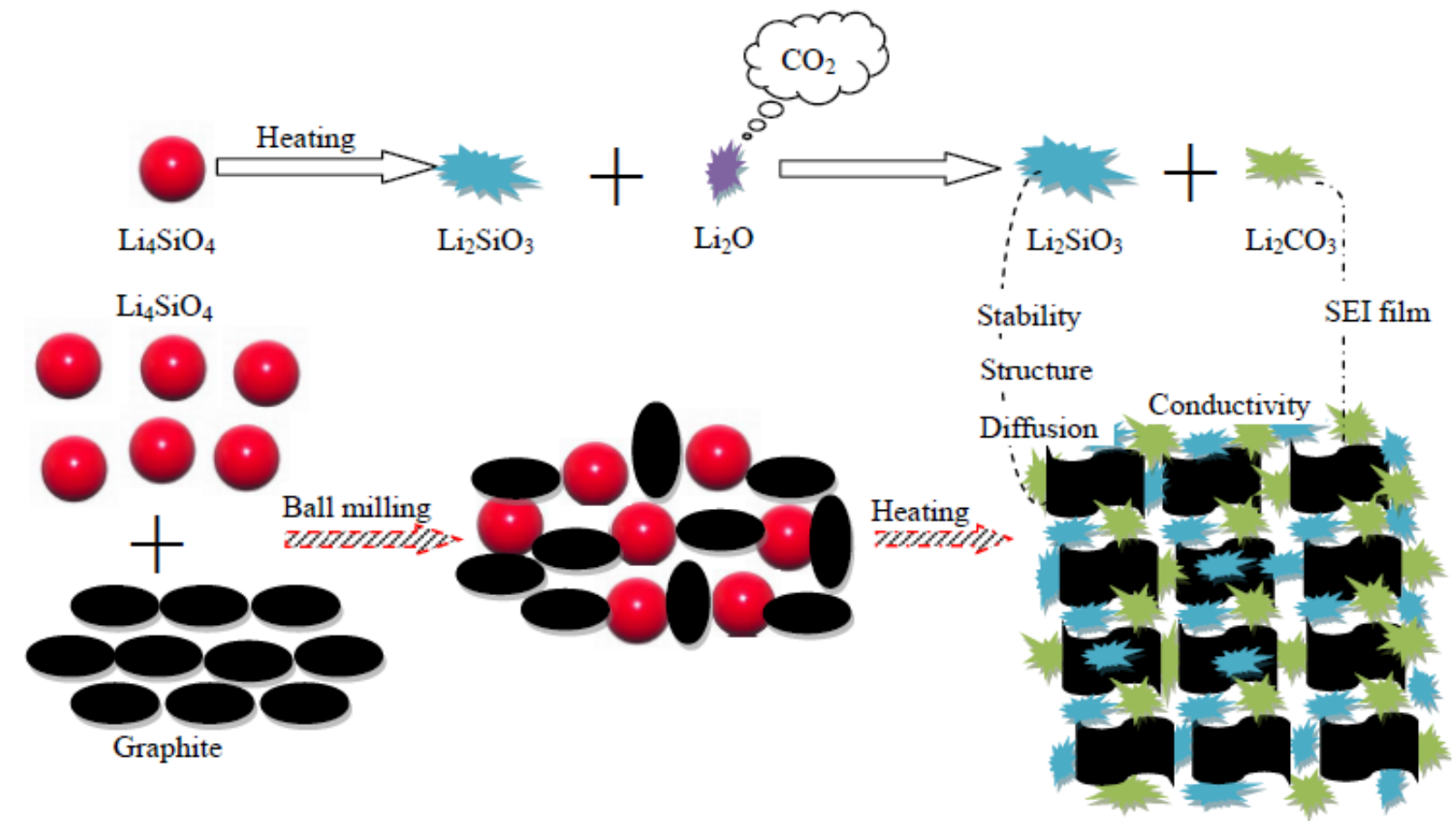

Figure 10 